\title{
Application of laser scanning cytometry in vascular smooth muscle remodeling
}

\author{
Dina Johar ${ }^{1,2} \cdot$ Sameh Magdeldin ${ }^{3,4}$
}

Received: 28 November 2017 / Revised: 2 February 2018 / Accepted: 20 February 2018 / Published online: 13 September 2018

(c) The Japanese Society of Hypertension 2018

\begin{abstract}
Pulmonary artery hyperplasia is the result of proliferation of the pulmonary arterial smooth muscles (PASM). Hypoxiainduced PASM proliferation in the fetus and the newborn is the primary cause of persistent pulmonary hypertension of the newborn (PPHN). This study was performed to characterize the utility of the Laser Scanning Cytometry (LSC) method in elucidating arterial cytoskeletal remodeling in an in vitro model of PPHN. The aim was to demonstrate the following: (a) LSC is a valid method for the analysis of nuclear and cytosolic fluorescence and (b) the cumulative effects of mechanical stretch together with hypoxia promote reactive oxygen species (ROS) formation. The molecular events in response to hypoxia and the mechanical overload of the pulmonary circuit were demonstrated in vitro by subjecting hypoxic cultured primary PASM or human airway smooth muscles (hASM) to repetitive stretch-relaxation cycles at rates comparable to dynamic stretch in vivo. The altered cytoskeleton in the form of filamentous to globular actin ( $\mathrm{F}: \mathrm{G}$ actin) ratio was imaged and quantified at the cellular level by LSC as an endpoint. LSC can remove the nuclear G-actin fluorescence from the total G-actin fluorescence. Pulsatile stretch was found to significantly increase the total endogenous ROS and superoxide anion release in normoxic and hypoxic conditions in primary PASM fibers. The effect of stretch was predominant in increasing superoxide anion release, only under hypoxic conditions. These findings, obtained by LSC in vitro are amenable to validation in any in vivo model of interest. The in vitro model is clinically relevant to human pulmonary vascular remodeling.
\end{abstract}

\section{Inroduction}

Neonatal PPHN is a rapid progressive vasculopathy that develops at a crucial stage in perinatal circulatory transition.

Electronic supplementary material The online version of this article (https://doi.org/10.1038/s41440-018-0077-6) contains supplementary material, which is available to authorized users.

\footnotetext{
Dina Johar

dinajohar@gmail.com

umjohar@myumanitoba.ca

1 Department of Physiology and Pathophysiology, Max Rady College of Medicine, Rady Faculty of Health Sciences, University of Manitoba, Winnipeg, Manitoba, Canada

2 Department of Biochemistry and Nutrition, Ain Shams University Faculty of Women for Arts, Sciences and Education, Heliopolis, Cairo, Egypt

3 Proteomics and metabolomics Unit, basic research, Children's Cancer Hospital 57357, Cairo, Egypt

4 Physiology Department, Faculty of Veterinary Medicine, Suez Canal University, Ismailia, Egypt
}

Normally, at term, fluids and blood in the neonatal lung are replaced with inspired gases, resulting in reduced pulmonary pressure and relaxation of the pulmonary artery $[1,2]$. Neonatal PPHN occurs when the pulmonary artery fails to relax [2] due to perinatal hypoxia, inflammation or direct lung injury $[3,4]$. The incidence rate of PPHN is $1-6$ per 1000 births [4]. In the United States, PPHN is responsible for $10 \%$ of admissions to the neonatal intensive care units [5, 6]. Thirty percent of PPHN infants die or require ventilator assistance [7].

As a sporadically occurring, lethal disease, PPHN is characterized by hypoxemia, pulmonary vascular constriction and arterial remodeling. End-stage PPHN histology is characterized by thickened vascular media and adventitia, smooth muscle (SM) hyperplasia and extracellular matrix deposition [8], impairing arterial distensibility [9], and resulting in a fixed and irreversible increase in pulmonary vascular resistance [1] [see schematic in Fig. 1, copyright is owned by Johar and Bernstein [10]]. Factors contributing to pulmonary artery hypertension (PAH) include prolonged vasoconstriction, hypoxemia, vascular remodeling, inflammatory cell migration and in situ thrombosis leading to vascular lesions [2, 11-13]. 


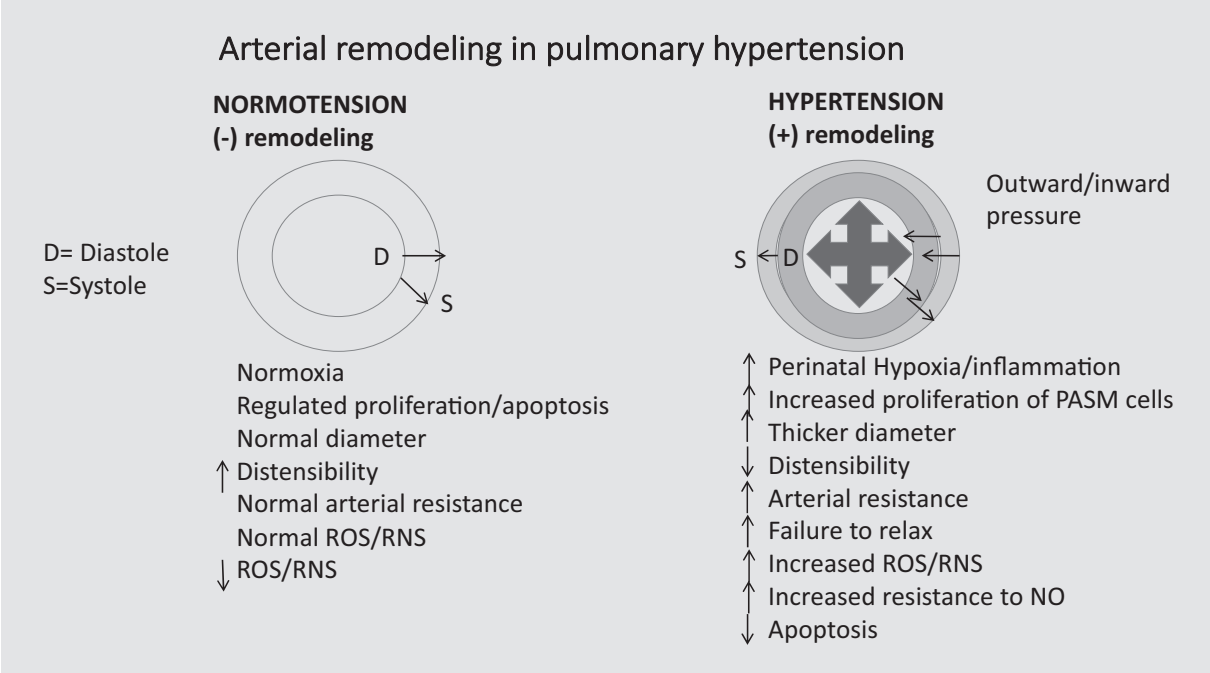

Fig. 1 Arterial remodeling in PPHN. The perfusion in the pulmonary circuit depends on the cardiac effort (systole). Normally, one cardiac beat causes $10 \%$ stretch. In PPHN, one cardiac beat causes less than $10 \%$ stretch. The cytoskeleton reacts to stretch. With a small strain $( \pm 5 \%$ from the artery resting length), there is heterogeneous response. With higher strain ( $\pm 10 \%$ from the resting length), a huge response occurs, such as a ripping damage to the cytoskeleton. High strain is associated with cell death due to the loss of adherence to the membrane. The arterioles change their diameter in response to local conditions such as

The SM composition of the hypoxic pulmonary arterial wall is influenced by selective cell cycle re-entry, reduced mitochondrial respiration [14], and initiation of apoptotic signaling $[12,15]$. The effect of hypoxia on pulmonary apoptosis is phenotype-dependent [16]. In synthetic myocytes, survival and proliferative signaling is enhanced by hypoxia [17]. Such signaling promotes vascular fibrosis; the fixed thickening of the arterial wall in turn increases resistance to vasodilator therapy such as nitric oxide (NO) [18]. The latter is a known vasodilator that can be exogenously inhaled to reduce pulmonary vascular resistance, but not systemic vascular resistance. Depending on the concentration, $>10$ particles per million worsens neonatal arterial oxygenation, with higher doses being potentially toxic. Chemical reactions with $\mathrm{O}_{2}$ or ROS release toxic nitrogen oxides and hydroxyl radicals that subsequently react with superoxide anion to form peroxynitrite radicals (ONOO-) ${ }^{*}$, which elicit pulmonary cellular injury. Hypoxia and NO cumulatively activate apoptosis of the contractile pulmonary artery SM, causing a contraction of this subpopulation during the cardiac cycle. In unresolved PPHN, pulsatile stretch turns into strain which eventually exacerbates and alters myocyte phenotype commitment [19] and induces the generation of ROS [20, 21].

Cyclic stretch triggers apoptosis selectively in contractile vascular myocytes $[22,23]$. Vascular pulsation is thought to be important for stretch-induced SM dilation and maintenance of arterial homeostasis without initiation of dedifferentiation and sympathetic or endocrine stimulation. Capillary walls permit exchange of oxygen and metabolites between blood and the surrounding interstitial fluids. Normally, diffusion distance is short and exchange is quick because the wall is thin. A high filamentous to globular actin $(\mathrm{F}: \mathrm{G})$ ratio increases stiffness, resulting in a thicker vessel diameter, higher pressure in remodeled versus non-remodeled vessels. Pulsation is non-harmonized due to the loss of distensibility. Remodeling is associated with hypertension, higher ROS, and lower antioxidant enzyme levels (Catalase, SOD 1,2,3, Glutatione peroxidase, NADPAH oxidases (NOX))

mural fibrosis [24]. How much stretch on the arterial wall, hypoxia and time are hypertensive and can lead to pulmonary overflow is not identified yet.

The role of actin polymerization in regulating cell cycle events in hypertensive myocytes is currently unknown. The altered cytoskeleton can be imaged at the cellular level by LSC, which quantifies fluorescence. The principle of quantifying nuclear fluorescence is as follows: In normal cell cycle phases (Go-G1, S and G2), nuclei stained with dye will look similar. If apoptosis starts scribing into the cell population, the nucleus begins to shrink and then fragments into smaller pieces. In this case, the amount of dye present in a single nucleus does not change, but becomes more concentrated. Thus, the total integrated fluorescence for the cell population will not change, but the dye being localized in a smaller volume will exhibit an increase in each pixel's fluorescence, while the total gray level values will be the same.

Reactive oxygen species are important signaling molecules that link vascular stretch with cell cycle entry or arrest. Endothelial cell strain triggers release of mitochondrial ROS to the cytosol [21, 25]. Moreover, vascular myocytes generate mitochondrial superoxide anion in response to stretch [26], activating biomechanical signaling pathways. The effect of mechanical strain on the ability of hypertensive pulmonary myocytes to handle oxidative stress is unknown. In this study, We thought to demonstrate that LSC, a method that utilizes a fluidic matrix to grow cells, can be 
employed to link the actions of pulsatile stretch and hypoxia in a PPHN oxidative environment and the occurence of tissue remodeling, using an in vitro model.

\section{Methods}

\section{The in vitro model}

All experimental protocols performed involving tissues from animals were in accordance with the ethical standards of the University of Manitoba. The guidelines of the Canadian Council on Animal Care on the use of animals were followed and all approvals were obtained from the University of Manitoba Animal Care Committee. This study model [as shown in supplementary Figure S.1A] does not depend on cells coming from a remodeled in vivo environment. Rather, it requires that the newborn pulmonary vessels are superbly plastic. It was not possible to extrapolate results from already remodeled circuits because the in vivo phenotype is rapidly lost when cells are grown in vitro. For this reason, it was necessary to examine the induction of cell fate decisions immediately after the application of stressors to primary neonatal PASM or human airway SM (hASM) cells in vitro. The resistant pulmonary arteries of 2 nd to 6 th generation were microdissected from the lungs of the term newborn $(<24 \mathrm{~h}$ old, $N=3$ ) piglets raised in normoxia (Fraction of inspired oxygen; $\mathrm{FiO}_{2}=0.21$ ). Minced vessels were recovered in cold $\mathrm{Ca}^{2+}$-free physiological buffer (KrebsHenselit, pH 7.4), then were recovered in cold Hepesbuffered saline (HBS) containing $(130 \mathrm{mM} \mathrm{NaCl}, 1.2$ $\mathrm{mM} \mathrm{MgCl} 2,5 \mathrm{mM} \mathrm{KCl}, 1.5 \mathrm{mM} \mathrm{CaCl}_{2}, 10 \mathrm{mM}$ glucose, $10 \mathrm{mM}$ Hepes, antibiotic/antimycotic mixture supplement, $\mathrm{pH}$ 7.4). The vessels were then washed with HBScontaining $20 \mu \mathrm{mol} \mathrm{CaCl}_{2}$, and minced. The minced vessles were then digested with collagenase $(1750 \mathrm{U} / \mathrm{ml})$, papain $(9.5 \mathrm{U} / \mathrm{ml})$, dithiothrietol $(1 \mathrm{mM})$ and BSA $(2 \mathrm{mg} /$ ml) in HBS-containing $20 \mu \mathrm{mol} \mathrm{CaCl}_{2}$, for $15 \mathrm{~min}$ at $37^{\circ} \mathrm{C}$ according to $[27,28]$. Cells dispersed by gentle trituration were collected by centrifugation at 1200 r.p. $\mathrm{m}$. for $5 \mathrm{~min}$, and then resuspended in complete Ham's F12 medium supplemented with L-glutamine, 10\% FBS, $1 \%$ penicillin, $1 \%$ streptomycin. Confluent cell cultures (70\%) were then plated on collagen-coated, flexer-cell 6well flexible culture dishes for two days in complete medium prior to experimentation. Stable $70 \%$ confluent SM monolayers were established, while serum-starved for the final 3 days in culture (with $1 \%$ survival factor; insulin/transferrin/selenium, Sigma) to synchronize in a contractile phenotype. Serum-starved contractile myocytes were allocated into four groups [1]: Normoxia resting $\left(21 \% \mathrm{O}_{2}, 5 \% \mathrm{CO}_{2}\right.$, balance $\left.\mathrm{N}_{2}\right)$ [2]. Normoxia mechanically stretched (cyclic stretch to total $\pm 5 \%$ from resting length, frequency $1 \mathrm{~Hz}$ ), which served as a control [3], Hypoxia $\left(10 \% \mathrm{O}_{2}, 5 \% \mathrm{CO}_{2}\right)$ resting, and [4] Hypoxia mechanically stretched as in [2]. According to previously published similar experimental setting [29], the described culture conditions achieves an average dissolved oxygen content of 4.5 and $2.3 \mathrm{mg} / \mathrm{L}\left[\mathrm{O}_{2}\right]$ in the normoxia and hypoxia cultures respectively, at the cell growth interface.

\section{Application of cell stretching}

Myocytes in mechanically stretched groups were placed on the flexer-cell strain unit (which applies uniform circumferential stretch to the collagen matrix beneath the cells to simulate the wall strain of vascular hypertension) for $72 \mathrm{~h}$ in a dedicated hypoxic or normoxic incubator without loading. The carbon dioxide $\left(\mathrm{PCO}_{2}\right)$ and oxygen $\left(\mathrm{PO}_{2}\right)$ pressures were maintained within $1 \%$ tolerance. All cells were seeded at a density of $70 \times 10^{3}$ cells per well in a 6well flexer-cell plate and then observed to avoid confluence [Figure S.1B].

After $72 \mathrm{~h}$ of applying the stretch or rest, cells were fixed with $4 \%$ paraformaldehyde (PFA) for LSC application or cell lysates collected in appropriate lysis buffers for protein assays. Cells in passage 0 (P0) were used in the experiments in a consistent fashion. Cells were counted using a haemocytometer to correct for detached cells before flexing [Fig. 2]. This model enables the in vitro assessment of the effect of a contractile force when applied to the vessel in a normal physiological status, in its optimal length, after it has been challenged by the treatment, and is either in the relaxed or contracted mode out of the lung. The vessel can be fixed and sections prepared. The vascular wall can be immunostained and signaling compared in either state, however, this is beyond the scope of this article.

\section{Hoechst nuclear staining for LSC}

After challenging PASM or hASM cells with stimuli in the flexer-cell plates, cells were fixed immediately with 4\% PFA, then permeabilized with fresh phosphatebuffered saline (PBS) containing $3.0 \%$ Triton X-100. After washing the cells, the nuclei were counter-stained by incubating with sterile PBS (containing freshly prepared cold working Hoechst 33342 solution $(10 \mu \mathrm{g} / \mathrm{ml}$ in PBS)) for $3 \mathrm{~min}$ at room temperature and light-protected. Cells were then washed several times with PBS to improve the background. Membranes were excised from plates and cells were allowed to air dry with the cell side facing up, protected from light for 30-45 min. Sections to be imaged were excised and mounted in mounting medium Prolong Diamond Antifade [Supplementary Figure 
S.2]. After 30 mins, another $70 \mu \mathrm{l}$ mounting medium and a cover slip were added in the dark to the cells' side facing up. Cells were kept at $4{ }^{\circ} \mathrm{C}$ until imaging was performed.

\section{The LSC scanning parameters}

An Olympus $1 \times 71$ inverted microscope was provided by the Children's Hospital Research Institue of Manitoba, Canada. The sourse of the lasers is gas $(488 \mathrm{~nm} ; 5-20 \mathrm{~mW}$ adjustable) and solid state diode lasers (405 and $633 \mathrm{~nm}$ ) for fluorescent excitations. The integral intensity of the blue fluorescence staining was quantified using the $\times 20$ objective for myocytes nuclei [Supplementary Figures S.3 and S.4] and $40 \times$ for cytosolic actin [Supplementary Figure S.5]. Fluorescence was collected using photomultiplier 1 (PMT1). Examples of the colors assigned to the PMT1 tubes are (488 nm (green), $405 \mathrm{~nm}$ (blue) and $633 \mathrm{~nm}$ (long red)). In nuclear staining, the blue channel was used to quantify Hoechst 33342 nuclear fluorescence [Figs. 3c, d and $4 \mathrm{a}, \mathrm{b}]$. For the blue emission, the laser used for excitation was the violet laser. The software used was iCys 3.4,

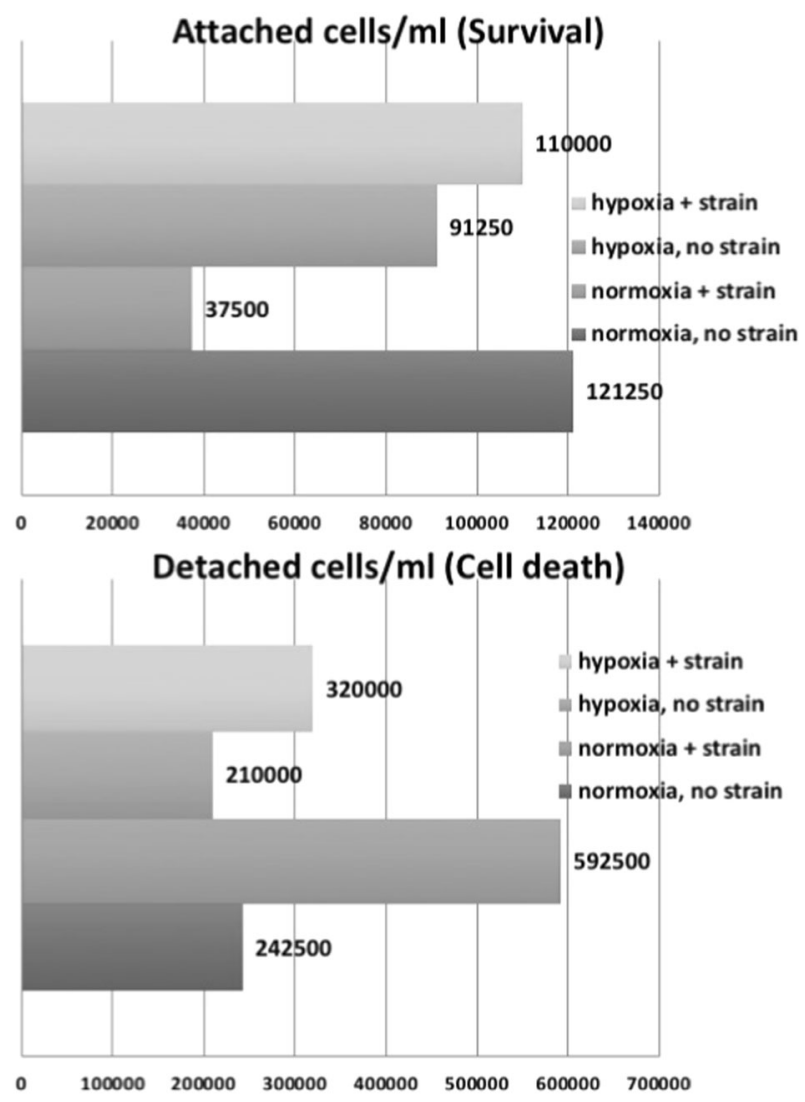

Fig. 2 Cell count of the attached viable cells (upper) is compared to cell count of the detached dead cells (lower) graph. The cells are synchronized in the contractile phase and therefore cell division was blocked. Seeding density is $70 \%$ prior to flexing in both experiments which provided direct cell cycle measurement comparable to that of a flow cytometer. The PMT detector used was a 14-bit camera. The used voltage units ranged from 1 to 10 . The scattergram $(X, Y$ position) creates a dot plot image of the scan area, with each dot representing an event i.e. (nucleus or actin filament) [Figs. 3a-d, $4 \mathrm{a}-\mathrm{d}, 6 \mathrm{a}-\mathrm{c}$ and supplementary Figures S.7, S.8].

The LSC provides a means to visualize and quantify cellular events and processes by identifying the edges of stained regions. An example of the red and green signals in the form of contour analysis of cytoplasmic F:G-actin ratios in cultured hASM cells is presented in [Figure S.5]. The total fluorescence from any color channel was integrated within the boundary of both the threshold and the integration contours were considered an event and identified for quantification [Supplementary Figure S.6]. The integral blue $=$ the total summed fluorescence (total summed gray level) within the boundary of the integration contour. The gain is always left at 100 . The step size is 1 . The settings of voltage, offset, min and max, the scatergram and the histogram in regions of interest in the nuclei and the cytoplasm were optimized and the parameters of the scanning process, contouring, and the modules used are illustrated in [Supplementary Figures S.4, S.5, S.7 and S.8). Galleries are presented in Supplementary Figure S.8.

\section{Phantom contour analysis of cytoplasmic F:G-actin ratios in cultured hASM cells by Phalloidin/DNASe-I staining using LSC}

Human ASM cells (HC82) were grown in a feeder medium, up to a $70 \%$ confluence prior to flexing. After cell flexing and fixation as described previously, cells were then washed to remove the residual fixative, then permeabilized with fresh Cyto-Tris buffered saline (TBS: $20 \mathrm{mM}$ Tris base, $0.154 \mathrm{M}$ Sodium Chloride $(\mathrm{NaCl}), 2 \mathrm{mM}$ Ethylene glycolbis ( $\beta$-aminoethyl ether)-N, $\mathrm{N}, \mathrm{N}^{\prime}, \mathrm{N}^{\prime}$-tetraacetic acid (EGTA), $2 \mathrm{mM}$ Magnesium Chloride $\left(\mathrm{MgCl}_{2}\right), \mathrm{pH}$ 7.2) containing 3.0\% Triton X-100 buffer (Sigma 93443) for 15 min. Later, cells were blocked for $1 \mathrm{~h}$ at room temperature with $1 \%$ Bovine serum albumin (BSA) in Cyto-TBS buffer, then washed with Cyto-TBS buffer.

Cells were stained with $1 \%$ BSA in Cyto-TBS cocktailcontaining Alexa Fluor Phalloidin 633 at 5:200 dilution (for F-actin in the myocytes cytosol Invitrogen Probes, red fluorescence, excitation range $632 \mathrm{~nm}$ and emission 647 $\mathrm{nm})$ concurrently with DNAse-I $(488 \mathrm{~nm})$ at 1:1000 dilution (for G-actin in the myocytes cytosol Invitrogen Probes, green fluorescence excitation range $488 \mathrm{~nm}$ and emission $525 \mathrm{~nm}$ ) for $1 \mathrm{~h}$ at room temperature in a humidified chamber. Cells were then washed with Cyto-TBS buffer while being shaken at low speed and nuclei were counter- 

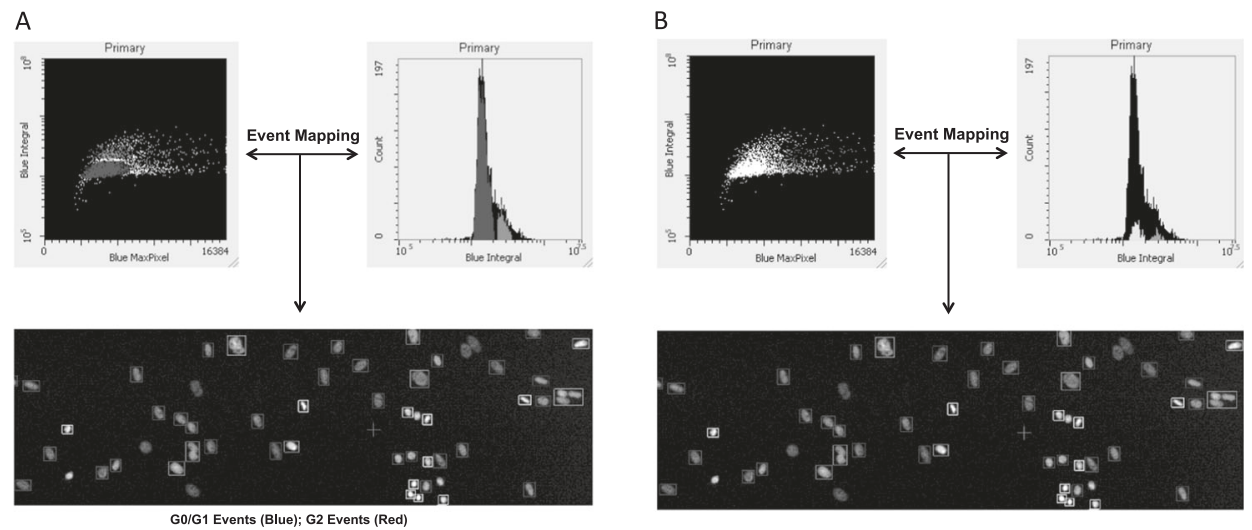
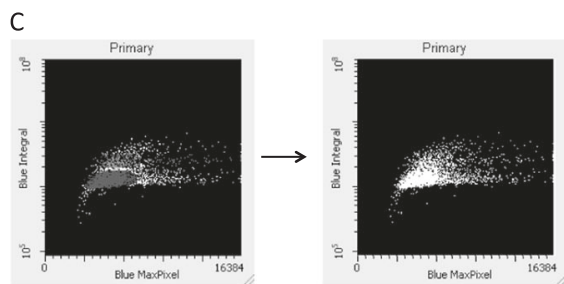

Quadrant Scattergram
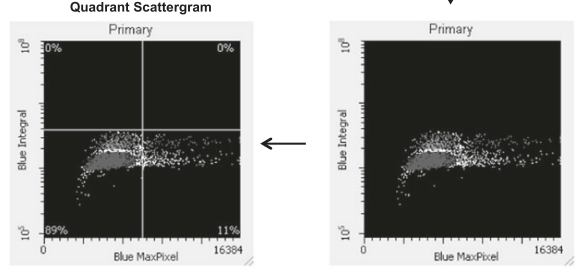

D
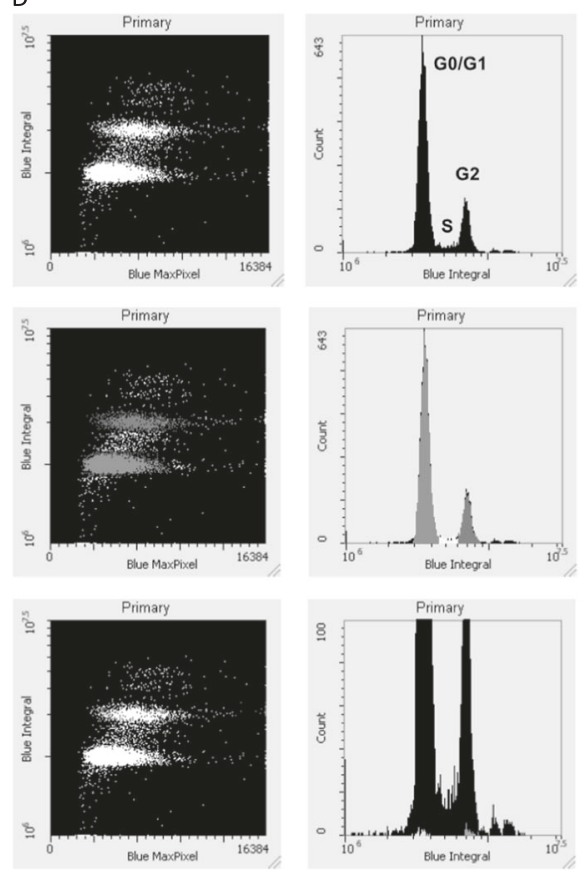
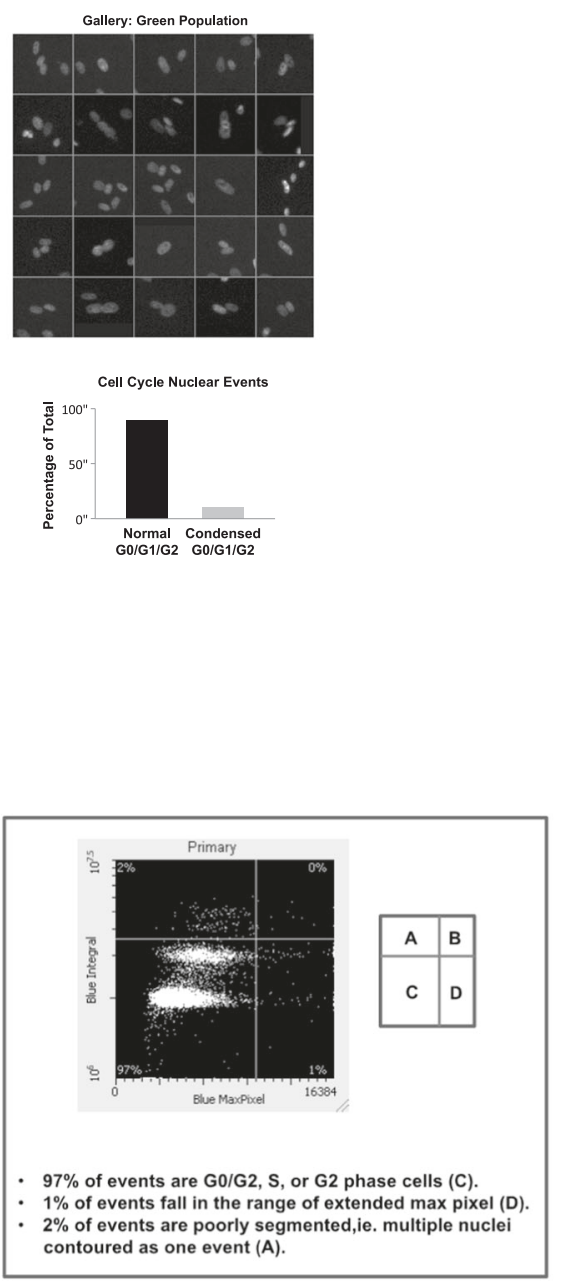

stained with Hoechst 33342 as described previously. This was followed by washing two times in double distilled water $\left(\mathrm{ddH}_{2} \mathrm{O}\right)$ while being shaken at low speed to provide a better background.
Membranes were excised from the plate, air-dried, mounted and assembled flat and in the dark, or were kept at $4{ }^{\circ} \mathrm{C}$ until imaging was performed. F- and G-actin staining were quantified as red and green integral intensity, adjusted 
Fig. 3 Cell cycle events. a Event mapping of PASM cells, no treatment. Distinct event populations can be identified and color coded within scattergrams or histograms and the color-coded events mapped to their specific coordinates within recorded scan field images. b Cell cycle events. Max pixel extensions of Go/G1 and G2 populations. Condensation of Go/G1 events is shown as cyan and of G2 events is in magenta. Nuclear condensation results in the cell cycle event populations with extended max pixel values in scattergram plots. Nuclear condensation can be indicative of either mitotic or apoptotic processes. Event mapping shows that condensed nuclei have a morphology consistent with apoptosis processes occurring within the population of cultured cells. $\mathbf{c}$ The horizontal/vertical division lines can be positioned manually, creating sectors of defined size (quadrants), $\mathbf{d}$ The normal growing population in Go/G1 was predominant $(97 \%$ of the total population)

to F-actin and then the same parameters were used for Gactin. A lattice grid of phantom contours for the measurement of F:G-actin fluorescence is shown in [Fig. 5]. The blue laser was used to collect green fluorescence.

\section{Isolation of cell-associated phantoms (the first LCS method)}

Phantom means a visual illusion that can define regions with distinctive boundaries when no real surrounding edges exist. Without some method of correction, used as is, quantification of G-actin fluorescence would include both nuclear and cytoplasmic signals. The LSC quantifies whole cell actin, and removes the nuclear G-actin fluorescence from the total $\mathrm{G}$-actin fluorescence. To achive this specific aim, cell-associated phantoms were separated further into nuclear and cytoplasmic populations. This was achieved through a scattergram blot of blue versus long red phantom fluorescence. The numerical values of such separation are shown in [Figs. 5c and 8c]. Fluorescence quantification can be expressed either as the summed integrated fluorescence of all phantoms or as the mean integrated phantom fluorescence [Figs. 5, 8 and 9]. Isolation of nuclear-associated phantoms and cell-associated phantoms is presented in Fig. 6.

\section{Isolation of nuclear-associated phantoms (the second LCS method)}

An alternative method is available for the isolation of nuclearassociated phantoms, using the experimental protocol's association module [Fig. 7]. By linking phantom contours with primary contours (blue channel-Hoechst nuclear fluorescence) through the association module, phantoms that were in direct physical contact with primary nuclear contours (associated), may be isolated as a distinct population-the cell associated nuclear phantoms. Associated events were displayed using a primary event scattergram and blotting nuclear (blue channel) fluorescence vs. associated long red channel phantom fluorescence. This scattergram may be termed the association scattergram [Fig. 8a-c].

\section{Bradford protein assay}

The radioimmunoprecipitation assay (RIPA) buffer (150 mM NaCl, $0.1 \%$ Triton X-100, 0.5\% Sodium deoxycholate, $0.1 \%$ Sodium dodecyl sulfate (SDS), $50 \mathrm{mM}$ Trishydrochrloride (Tris-HCl), $\mathrm{pH} 8$, was used to prepare the whole cell lysates. $100 \mu \mathrm{l}$ of the RIPA buffer was added to 2 wells of a 6-well flexer-cell plate. Prior to usage (Sodium fluoride (NaF) $50 \mathrm{mM}, 200 \mathrm{mM}$ Phenyl methyl sulfonyl fluoride (PMSF) in Dimethyl sulfoxide (DMSO), Sodium orthovanadate $(\mathrm{NaOV}) 250 \mathrm{mM}$, Protease inhibitors $(10 \mu \mathrm{L} /$ $1 \mathrm{ml}$ buffer) and Phosphatase inhibitor (10 $\mu \mathrm{l} / 1 \mathrm{ml}$ buffer)) were freshly added to the RIPA buffers, which was then filter-sterilized through $0.22 \mu \mathrm{M}$ membrane. Lysates $(2 \mu)$ were diluted 1:100 for protein concentration and measured in 96 well plates at $595 \mathrm{~nm}$ using a spectrophotometer (Gen5 software). Using BSA $(1 \mu \mathrm{g} / \mu \mathrm{l})$ as a standard, Bradford reagent was used to draw a standard curve for protein concentration. A replicate of 3 wells out of 3 independent animals was used consistently for statistical analysis.

\section{Expression of SM differentiation markers}

The PASM cells were examined by immunoblotting for protein markers of SM differentiation such as $\alpha-S M$ actin, $\beta$-actin and SM desmin [Fig. 9a]. Immunoblot quantification of the basal level of SM differentiation markers, cell cycle regulatory proteins and their phospho-specific partners was done to characterize hASM cells, to confirm the expression of the contractile phenotype in starved cells, and to compare this expression to the non-starved (synthetic) phenotype as shown in [Fig. 9b]. Cell lysates were used in a concentration gradient manner ranged from $1-10 \mu \mathrm{g} / \mathrm{lane}$ in $6 \times$ Laemmli buffer (SDS $12 \mathrm{~g} / 100 \mathrm{ml}$, bromophenol blue $60 \mathrm{mg} / 100 \mathrm{ml}$, glycerol $47 \mathrm{ml}, 12 \mathrm{ml}$ of $0.5 \mathrm{M}$ Tris $\mathrm{pH} 6.8, \mathrm{ddH}_{2} \mathrm{O} 12 \mathrm{ml}$ ). The protein lysates were added to $6 \times$ Leammli buffer at 1:5 ratio, then were boiled for $5 \mathrm{~min}$, cooled and then dithiothretol (DTT) $(9.3 \mathrm{~g} / 100 \mathrm{ml}$ protein/Leammili mixture) was added before loading. Protein bands were separated by SDS polyacrylamide gel electrophoresis (PAGE) using 12\% gels and then transferred to polyvinylidene difluoride (PVDF) membrane. The PVDF was blocked using 5\% milk in TBS-Tween (TBST), and then incubated with each of the following antibodies consecutively: mouse anti $\alpha$-SM actin (Sigma A2547); rabbit anti desmin (Sigma); rabbit anti protein kinase B (AKT) and phosphorylated (pAKT) (Cell Signaling); rabbit anti extracellular regulated kinase (ERK1), ERK2, pERK1/2 (Cell Signaling); mouse anti cellular Rous sarcoma virus 


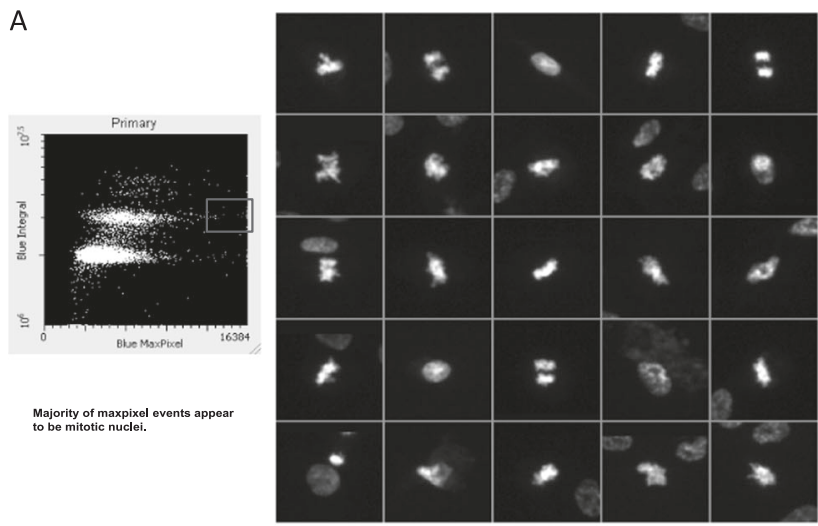

C
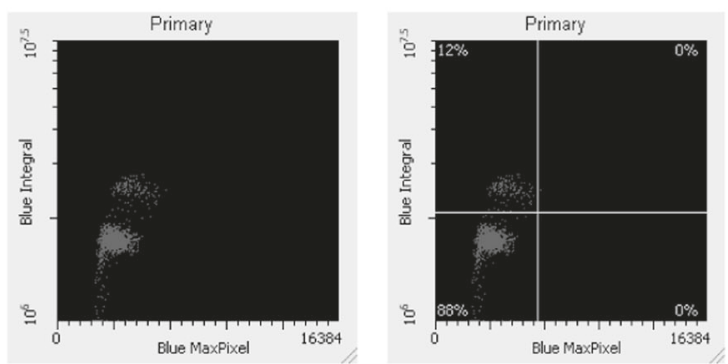

$E$

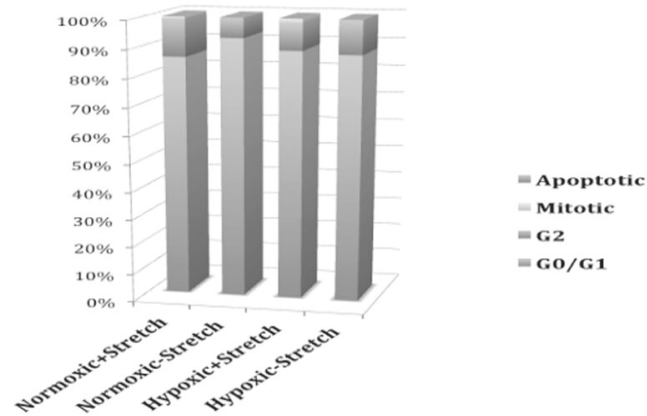

Fig. 4 Quantification of cell cycle nuclear events by LSC. a Gallery and field image of region of interest (ROI), i.e., R4 (G2 events). $X$, $Y$ scattergram of hypoxia together with stretch representing regions of interest. b Scattergram and quadrant statistics. Hypoxia without stretch (The predominant proportion of normal cells is in Go/G1 phase $84 \%$ of total, and a small proportion is in $\mathrm{G} 2$ phase $15 \%$. S phases: $1 \%$. No apoptosis). c Normoxia together with stretch. d Normoxia without stretch. e Apoptosis and cell cycle analysis. Hypoxia together with

protooncogen Src and p-Src (Cell Signaling). The membranes were stripped and re-probed with mouse anti $\beta$ actin to control for differences in protein loading (Sigma, diluted 1:5000 in 1\% BSA in 1\% TBS), followed by $2 \mathrm{~h}$ incubation with the Horse radish protein HRP-conjugated goat anti-mouse antibody or anti-rabbit secondary antibody (diluted 1:5000) in 1\% free-fat milk in TBST at room temperature). Representative results of three separate experiments using Bio $\mathrm{Rad}$ 161-0374 molecular weight markers are shown in [Fig. 9a, b]. All bands were visualized using the Lumi-light Western blotting substrate
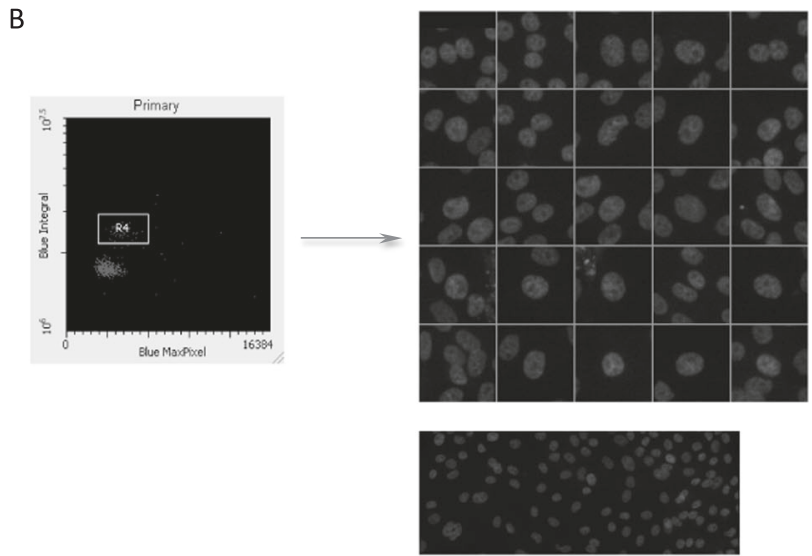

D
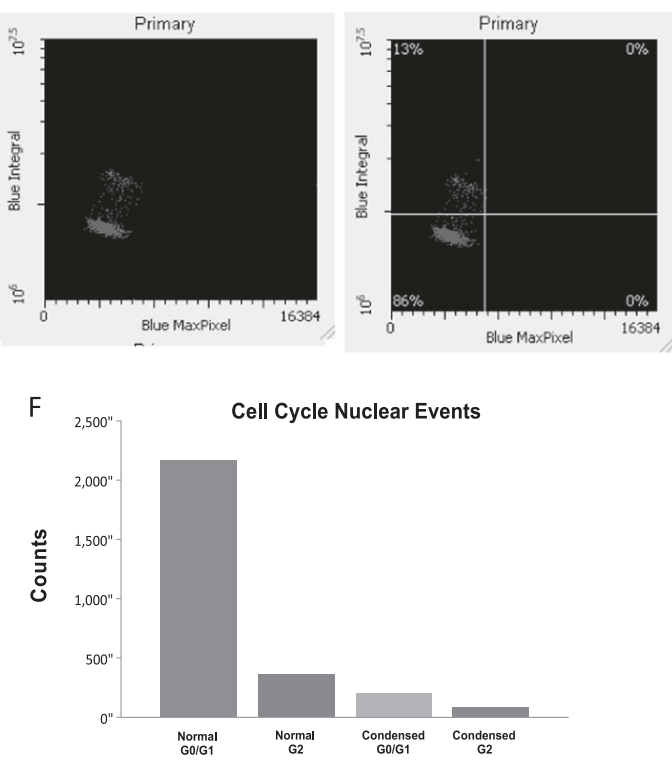

stretch: $(\mathrm{Go} / \mathrm{G} 1=88 \%, \mathrm{G} 2=12 \%, \mathrm{~S}=0 \%$, apoptosis $=0 \%)$. Normoxia with stretch: (Go/G1 86\%, G2 13\%, M 1\%). Normoxia without stretch: (Go/G1 93\%, G2 7\%). f Statistics. The cytometer software contains a statistic package allowing for the selection of various statistical parameters for data analysis. For the present analysis, the statistical parameter "count" was used for the assessment of the percentage of nuclear events in various stages of the cell cycle. $N=3$ biological replicates

(Roche Diagnostics, Mannheim, Germany). The intensity of the bands was detected using the Fluorochem system and quantified with Alpha Ease FC, version 6, software.

\section{Simultaneous quantification of cytosolic ROS by 2,7 dichlorodihydrofluorescein diacetate (DCF) and superoxide by dihydroethidium (DHE) fluorescence}

Working solutions of DCF/DHE were prepared concurrently from stock solutions: stock cell permeable dichlorodihydrofluorescein diacetate $\left(\mathrm{H}_{2}\right.$ DCF-DA) (Sigma, 


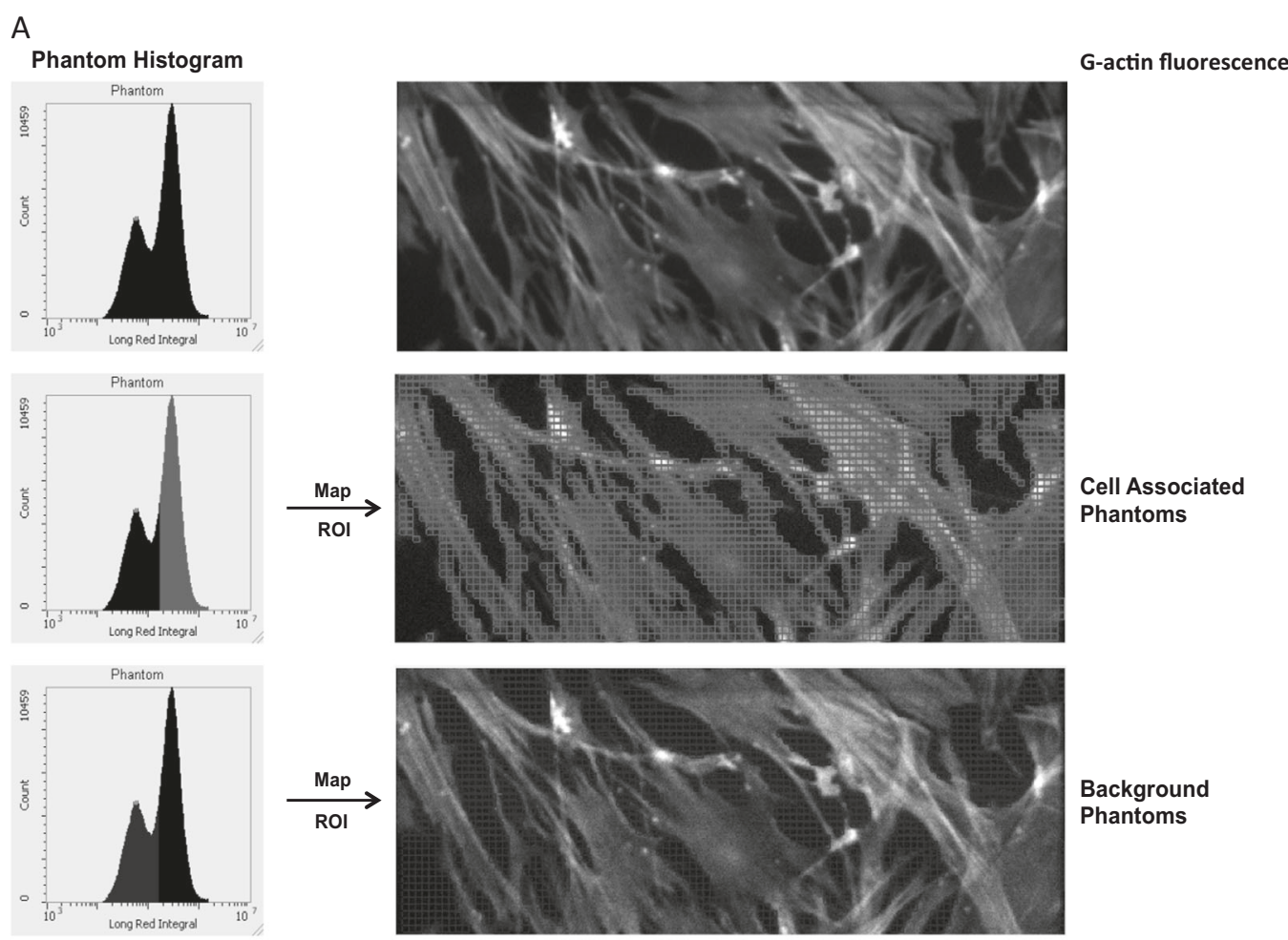

B

Quantitation of F-Actin Fluorescence (Long Red Channel)

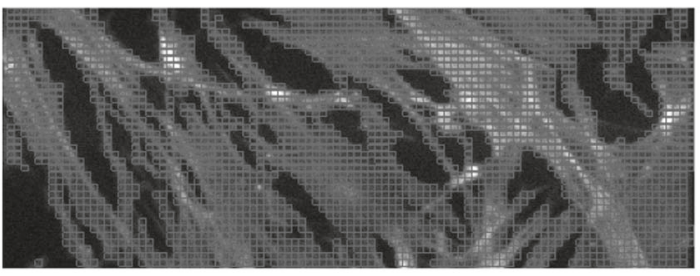

Cell Associated

Phantoms

Quantitation of G-Actin Fluorescence (Green Channel)

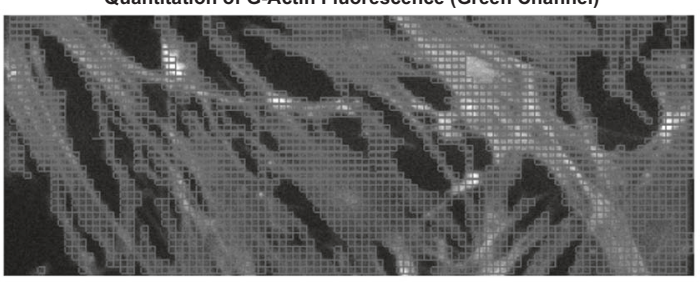

Cell Associated -

Cytoplasmic Phantoms

$C^{*}$

Total F-Actin

Cytoplasmic G-Actin

Phantom Integral Long Red Sum Phantom Integral Green Sum F-Actin/G-Actin Ratio (Sum)

$74,520,809,222$

Phantom Integral Long Red

Mean

344,232
23,094,202,036

Phantom Integral Green

Mean

111,163

\section{2}

F-Actin/G-Actin Ratio (Mean)
$0.0024 \mathrm{~g}$ in $50 \mu \mathrm{l}$ DMSO); DHE (Sigma, $0.0015 \mathrm{~g}$ in $50 \mu \mathrm{l}$ DMSO) avoiding light, to obtain $100 \mu \mathrm{M}$ working solutions of DCF and DHE. The DCF assay was modified after Wang and Joseph [30] and the DHE assay was modified after Munzel et al [31], respectively as follows. Attached cells were washed with $1 \times$ PBS twice, then treated with trypsin 
$0.75 \mathrm{ml}$ per well. Incomplete (serum-free) Ham's F12 medium $(0.75 \mathrm{ml})$ was added and cells were collected in microfuge tubes to a total volume of $1.5 \mathrm{ml}$, then

Fig. 5 Phantom contour analysis of cytoplasmic F:G actin ratios in cultured primary PASM cells. a Identification of background and cell associated phantom populations (long red channel). The cellassociated phantom contour population is used for the quantification of F-and G-actin fluorescence. b To remove the nuclear G-actin fluorescence from the total G-actin fluorescence, cell-associated phantoms must be separated further into nuclear and cytoplasmic populations. This is achieved through a scattergram plot of blue versus long red phantom fluorescence, the numerical values of such separation are shown in C. c Fluorescence quantification can be expressed either as the summed integrated fluorescence of all phantoms or as the mean integrated phantom fluorescence centrifuged at $1000 \mathrm{rpm}$ for $7 \mathrm{~min}$. The pellet was resuspended in $1 \mathrm{ml}$ incomplete Ham's F12 medium.

One ml working DCF or DHE was added to each $10^{6}$ cells after normalizing for the cell number per treatment, i.e., (hypoxia together with or independent on stretch) and (normoxia together with or independent on stretch). Cells were incubated at $37^{\circ} \mathrm{C}$ for $30 \mathrm{~min}$, centrifuged at $1000 \mathrm{rpm}$ for $5 \mathrm{~min}$; then washed $2 \times$ with $1 \times$ PBS to wash out the extracellular DCF or DHE. Cells were resuspended $1 \mathrm{ml} \mathrm{F12} \mathrm{per}$ $10^{6}$ cells for the number of 3 well replicates per treatment. The intracellular DCF fluorescence was read at excitation $485 \mathrm{~nm}$, emission $520 \mathrm{~nm}$ and gain 1500 , at time 0 , and every $30 \mathrm{~min}$ thereafter while being incubated at $37^{\circ} \mathrm{C}$. The intracellular DHE fluorescence was read at excitation
A

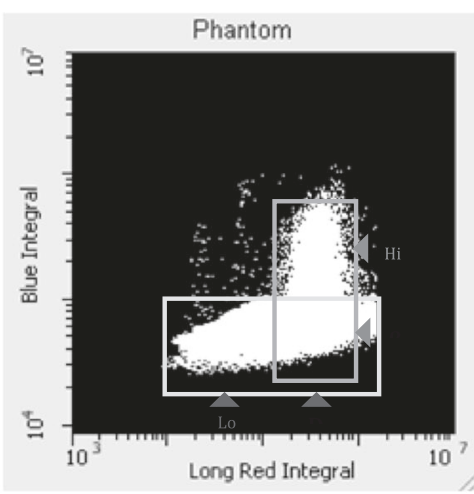

B

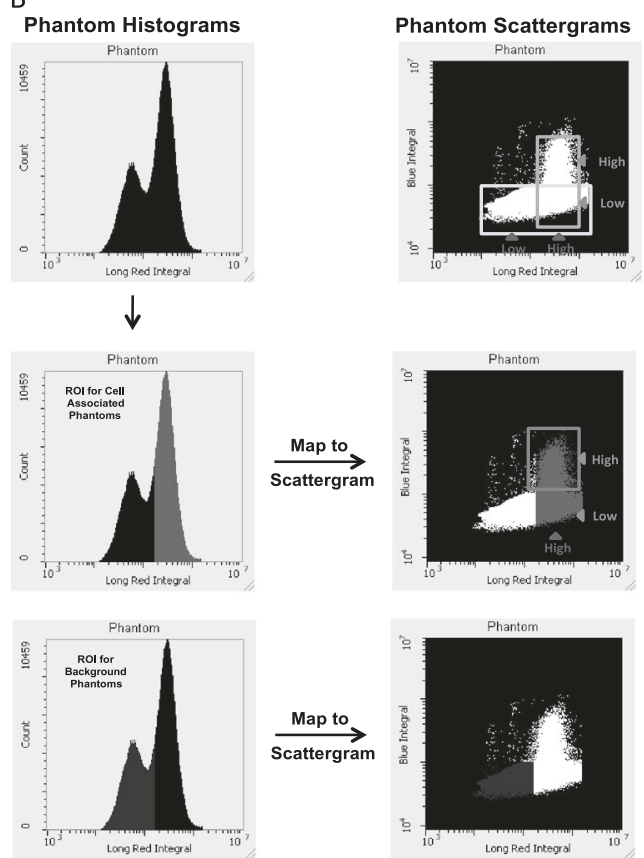

Fig. 6 Isolation of nuclear-associated phantoms. a A scattergram blot of blue (Hoechst) nuclear fluorescence versus long red (F-actin) cytoplasmic fluorescence reveals distinct phantom populations: Phantoms with low blue/low long red and low blue/high long red fluorescence (yellow box). Phantoms with low blue/high long red and high blue/high long red fluorescence (orange box). b Cell-associated
C
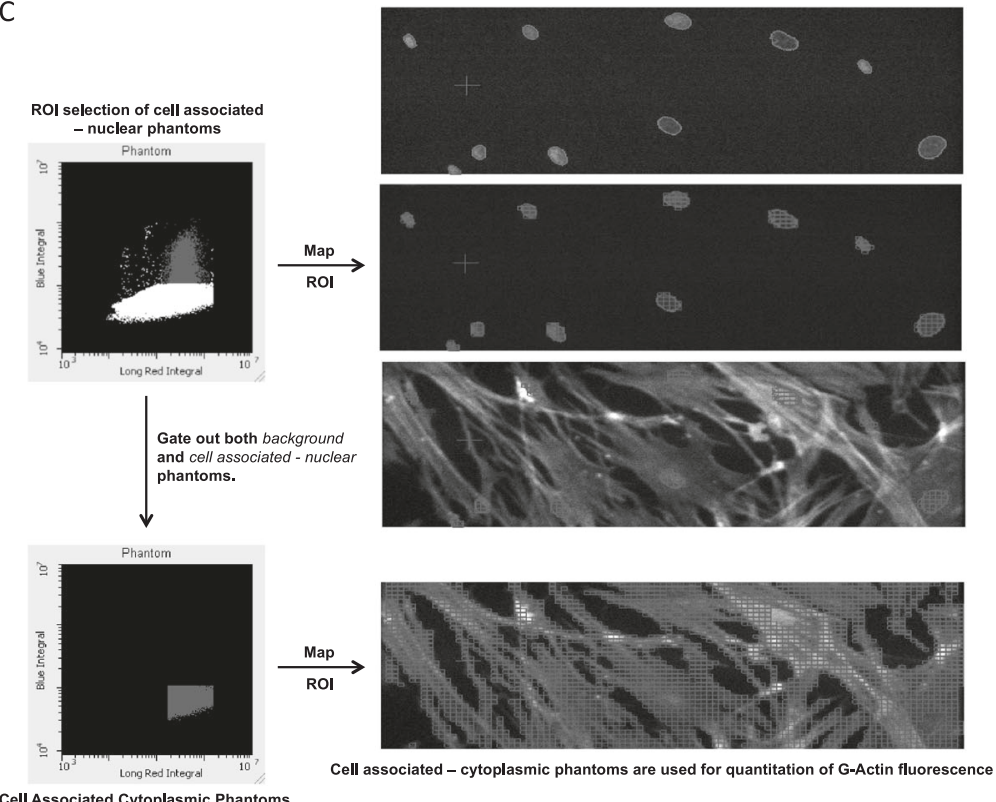

Cell Associated Cytoplasmic Phantoms phantoms previously identified in the phantom histogram, map to regions of low blue/high long red and high blue/high long red fluorescence within the phantom scattergram. c Phantoms with both high blue/high long red fluorescence (green box) are likely the cellassociated-nuclear phantoms. ROI region of inetrest 


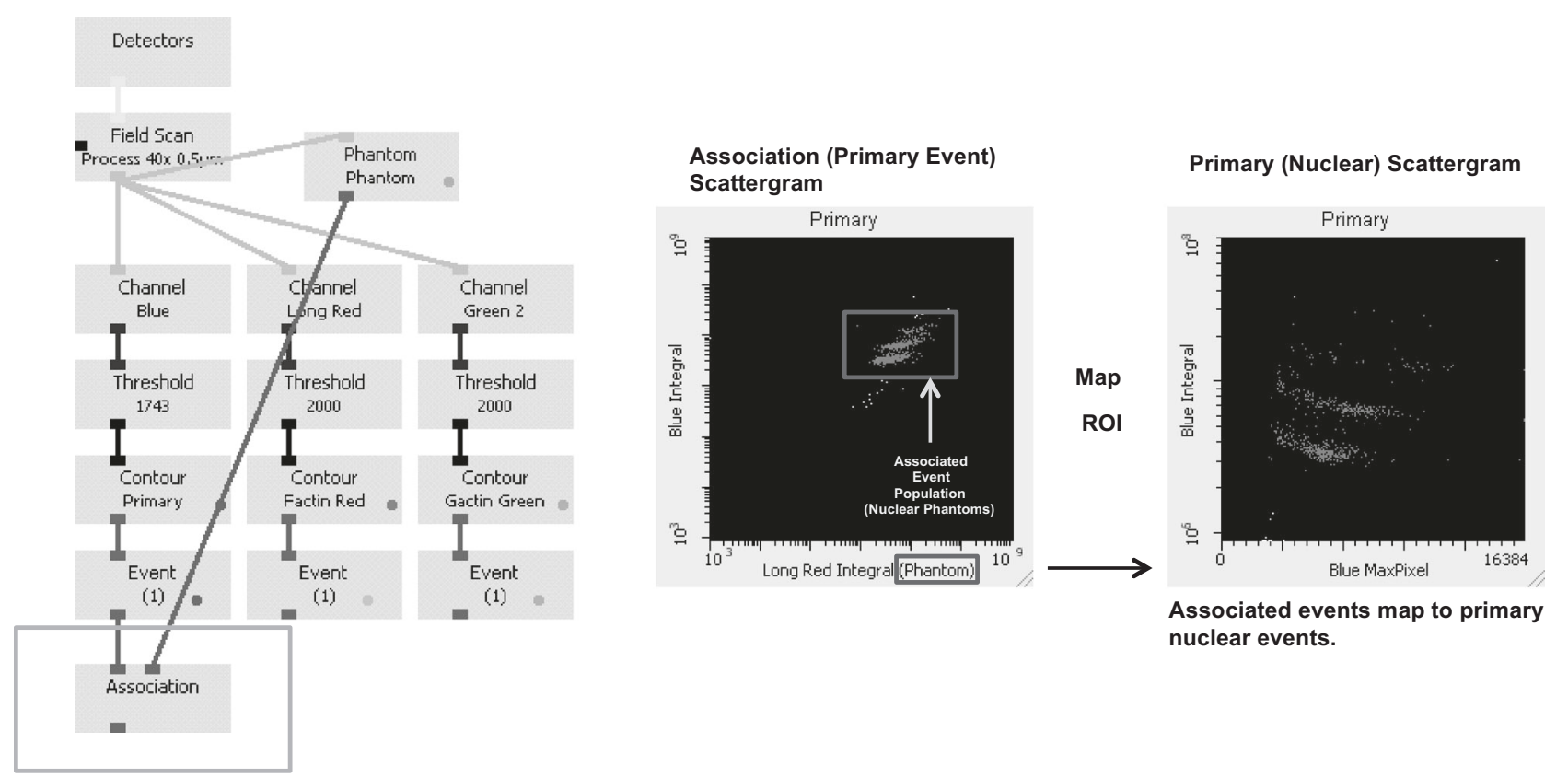

Association Module

Fig. 7 Nuclear associated phantom module. Phantoms link only phantom contours that are in direct contact with the primary contour (blue fluorescence) trough the association module. The primary contour is the nucleous phantom contour. The associated events are

488-510 nm, emission 590-620 nm and gain 1500, at time 0 , and every $30 \mathrm{~min}$ thereafter while being incubated at $37^{\circ} \mathrm{C}$.

\section{Statistical analysis}

Data were presented as mean \pm SD. The PASM cells were compared within each matched phenotype groups, i.e. (hypoxia together with stretch) and (hypoxia independent on stretch) were compared to (normoxia together with stretch) and (normoxia independent on stretch), respectively, using the two-way ANOVA. DCF and DHE data were analyzed with PRISM 6.0 (GraphPad Software, Inc. San Diego, CA). The two-way ANOVA, followed by Bonferroni test for multiple comparisons was performed on three independent samples per group. An Alpha ( $p)$ level of $<0.05$ presented significance. The statistical analysis for the isolation of cytoplasmic phantom was confirmed by two methods using the iCys 3.4 software.

\section{Results}

\section{The normoxic cells have a higher susceptibility to the adverse effects of strain than the hypoxic cells}

Haemocytometer was used to quantify cell detachment (or viability) during the incubation and the starting confluence pre-scanning [Fig. 2]. The highest cell detachment rate occured in the normoxic population. The relationship displayed using primary event scattergram and blotting nuclear (blue channel) fluorescence vs. associated long red channel phantom fluorescence. This scattergram may be termed the associated scattergram

between cell death and survival in PASM cells in the normoxic population was inverse, normal and dynamic (strain-dependent, responsive). That is when cell death increases, survival decreases, demonstrating that strain promoted cell detachment or death. In the hypoxic population, the relationship between cell death and survival was inverse, however, cell death (detachement) was strain-independent.

\section{Immunoblot quantification of the basal level of SM differentiation markers}

Immunoblotting results shown in Fig. 9 confirm the expression of SM differentiation markers. Serum deprivation for $48 \mathrm{~h}$ upregulated the basal expression of key proteins involved in different biomechanical and hypoxia pathways and their phospho-specific partners except for Src and pSrc [Fig. 9b].

\section{A small percentage of condensed nuclei have morphology consistent with apoptosis}

Nuclear condensation in non-treated PASM cells can be indicative of either mitotic [Fig. 4a and Supplementary Figure S.4] or apoptotic processes [Fig. 3a, b], similarly to non-treated hASM [Supplementary Figure S.8]. The mitotic events presented the majority of the high max pixel population [Fig. 4f], whereas apoptotic events represented a minor $(1 \%)$ percentage of the total event 

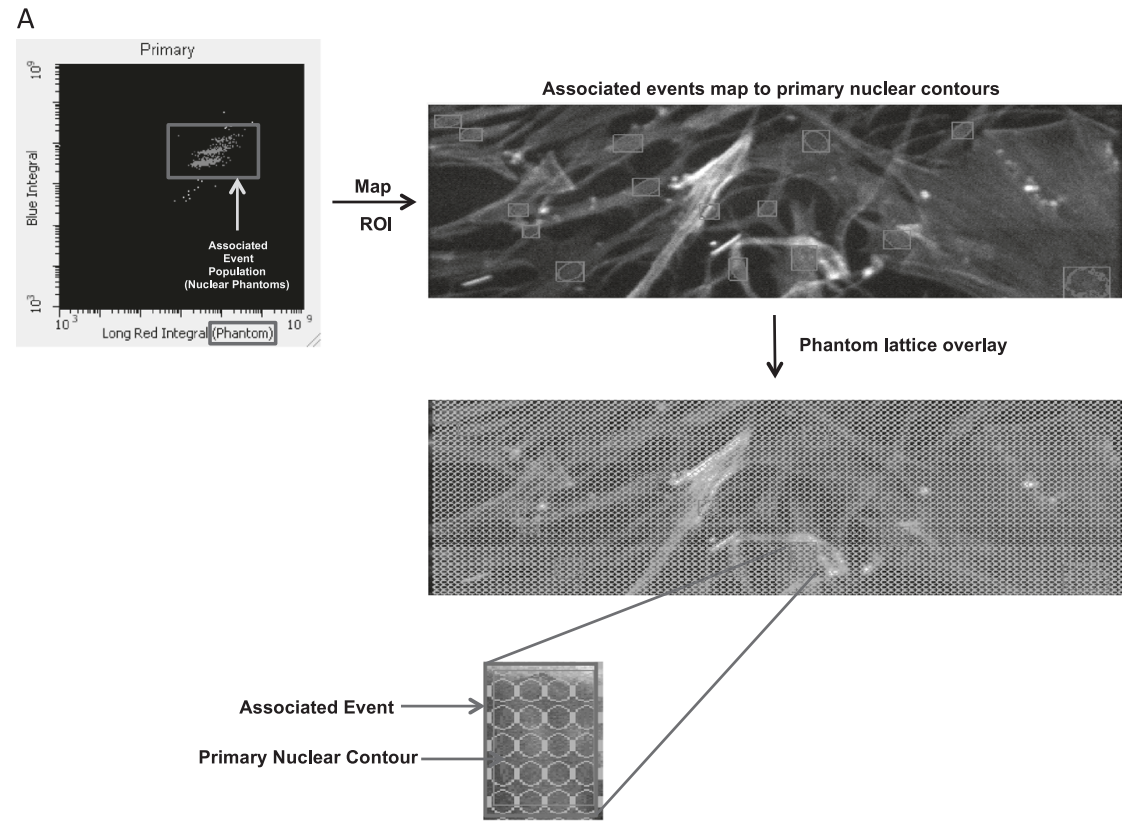

B

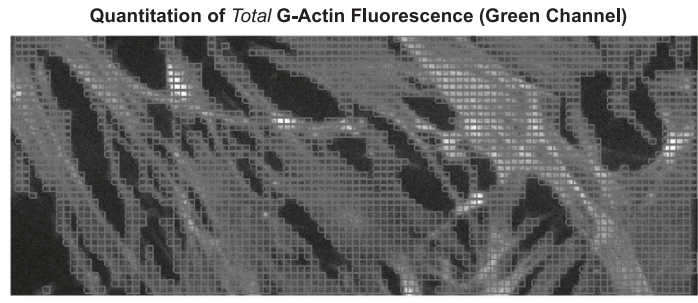

Cell Associated

Phantoms

Quantitation of Nuclear G-Actin Fluorescence (Green Channel)

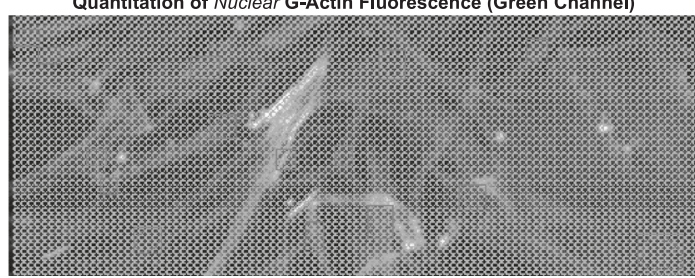

Associated Event

Phantoms

(Purple Boxes Only)

\section{C*}

Total F-Actin

\section{Phantom}

Phantom
Integral Long

Red Sum

Phantom Integral Green

Sum (Total)

Green Sum (Nuclear)

Nuclear G-Actin

Cytoplasmic G-Actin

$74,520,809,222 \quad 26,136,680,654$

$3,142,947,131$
Fig. 8 a An alternative method of isolating nuclear-associated phantoms. b The associated event population contains only those phantom contours in direct contact with the primary nuclear contour. $\mathbf{c} *$ In this
$22,993,733,523$

Corrected Phantom Integral Green
Sum Total

Corrected Phantom Integral Green
Sum Total

3.2

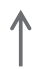

\section{Result consistent with previous methodology}

method, the phantom population is consistent with the cell-associated nuclear phantom population isolated by the previously described LSC method 
population [Fig. 4e]. Different treatments (hypoxia together or independent of stretch; normoxia together or independent of stretch) did not change the distribution of the cell cycle phases. The normal growing population was predominantly $(97 \%)$ in Go/G1 as shown in [Figs. 3c, d and 4e, f].

\section{The validity and reproducibility of LSC application in quantifying the cumulative effects of hypoxia and cyclic mechanical stretch on cytoskeleton remodeling in myocytes}

The altered $F: G$ actin ratio as a measurable endpoint for cytoskeleton organization upon exposure of PASM or hASM cells to hypoxia together or independent on strain is quantified by two LSC modules that can generate the same ratios, and hence are reproducible. F:G actin ratios scored 3.2 (sum) or 3.1 (mean) in cultured hASM cells by two alternative methods [Figs. 8 and 9], demonstrating that LSC is a valid method for visualizing and quantifying actin depolymerization in hypertensive myocytes.

\section{Mechanical stretch and hypoxia alter the defence against ROS}

The changes in the emission of DCF and DHE normalized towards the control group (normoxia together with stretch) are presented in Fig. 10. Pulsatile strain significantly increased the total cytosolic ROS (primeraily $\mathrm{H}_{2} \mathrm{O}_{2}$ ) and endogeneous superoxide anion release in normoxic and hypoxic conditions in primary PASM fibers [Fig. 9]. The effect of strain was predominant in increasing the superoxide anion release only under hypoxic conditions [Fig. 10].

\section{Discussion}

\section{The behavior of the myocytes during stretch is comparable to the behavior of the arterial wall according to LSC}

This study characterized the utility of the LSC in elucidating arterial cytoskeletal remodeling in vitro. While hypertensive states are traditionally modeled by increased pulsatile mechanical stretch, a review of Echocardiography and Magnetic Resonance Imaging (MRI) data indicated that in fact hypertensive states may be marked by an increased diastolic vascular diameter and loss of distensibility, with limited pulsatile deformation during systole [32-34]. The MRI is a useful method for imaging cardiovascular tissues and as a means for measuring the arterial diameter. When the vessel is stretched at the heart rate of $1.5 \mathrm{~Hz}$ (the physiological inspiration/exhalation

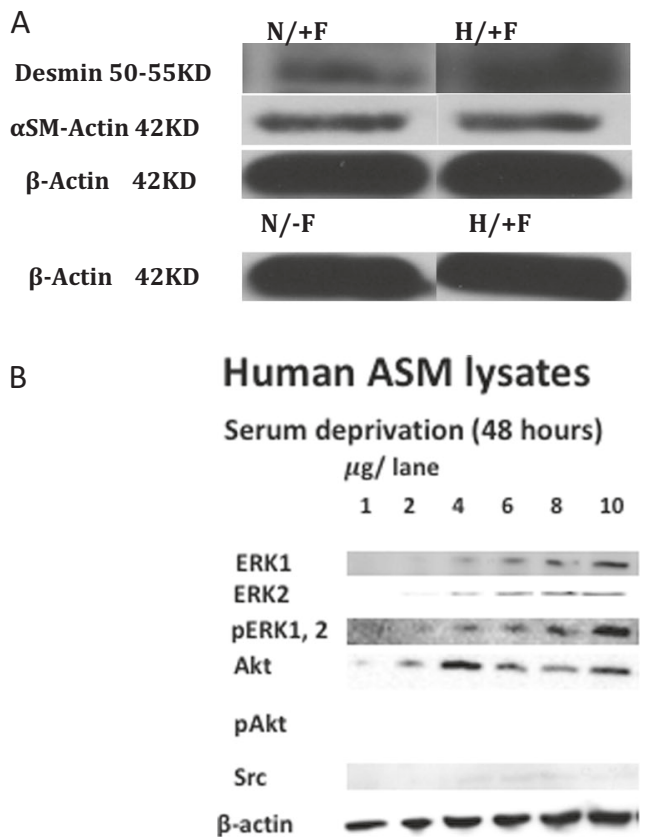

Serum fed ( 48 hours)

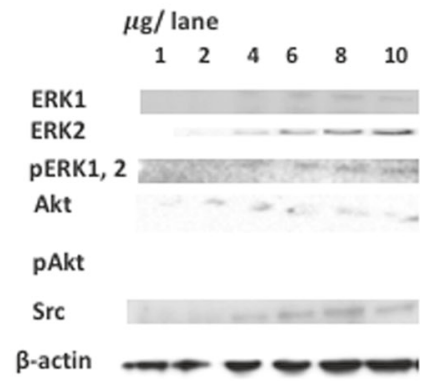

Fig. 9 a Examination of SM markers in hypertensive PASM or (b) normal hASM lysates to confirm the basal expression. b Levels of SM markers $\alpha$-actin, $\beta$-actin, desmin in a concentration gradientdependent manner that ranges from 1 to $10 \mu \mathrm{g}$ hASM cell lysate in relation to different conditions of hypoxia and flexing. $\mathbf{b}$ Concentration gradient shows the basal levels of ERK1/2, pERK1/2, AKT, Src, as they are expressed in serum fed and serum deprived hASM, and the lack of pAKT expression. $\beta$-actin is a reference protein. Cropped gels are presented for both panels. $N$ normoxia, $F$ flexing, $H$ hypoxia

frequency characteristic of the animal), we get a $1 / 4$ of the response we may get when using the non-physiological frequency. Although authors [35-37] could get a maximum deformation at faster rates (15-18\%), these rates are non-physiological. The maximum deformation we can get during pulsation is about $\pm 5 \%$ of the resting vessel wall length. In PPHN, we can get less deformation. This is contradictory to the way controls are usually designated, wherein the control is static (unstrained), and the strained is hypertensive. Cell structure indicates the behavior of the cells during stretch and comparing that to the behavior of the arterial wall is amenable by LSC. A gradient stretch can be looked at and optimized, however, this is beyond 
Fig. 10 Pulsatile strain increased total ROS and superoxide release significantly in normoxic and hypoxic conditions. a Total cytosolic ROS is quantified by the change in DCF-DA fluorescence from primary PASM fibers. b Endogenous superoxide radical is quantified by the change in DHE signal at $30 \mathrm{~min}$ from basal induction. For both assays an average of $5 x$ $10^{5}$ stimulated cells/treatment was analyzed during two consecutive $30 \mathrm{~min}$ periods at $37^{\circ} \mathrm{C}$ at excitation $485 \mathrm{~nm}$, emission $520 \mathrm{~nm}$ and gain 1500 . $P<0.05$ represents significance, $* * *$ highly significant, ratio to normoxic strain. $\mathrm{N}+\mathrm{S}+$ normoxia together with stretch; $\mathrm{N}+\mathrm{S}-$ normoxia independent on stretch; $\mathrm{H}+\mathrm{S}+$ hypoxia together with stretch; $\mathrm{H}+\mathrm{S}-$ hypoxia independent on stretch
A) Total ROS in PASM cells DCF ASSAY
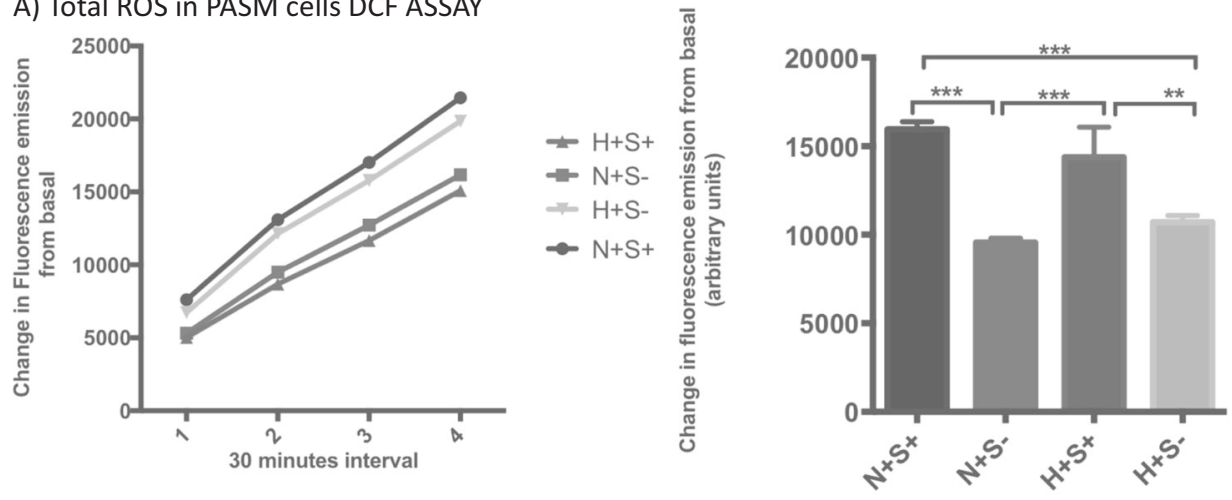

B) Endogenous superoxide anion in PASM cells DHE assay

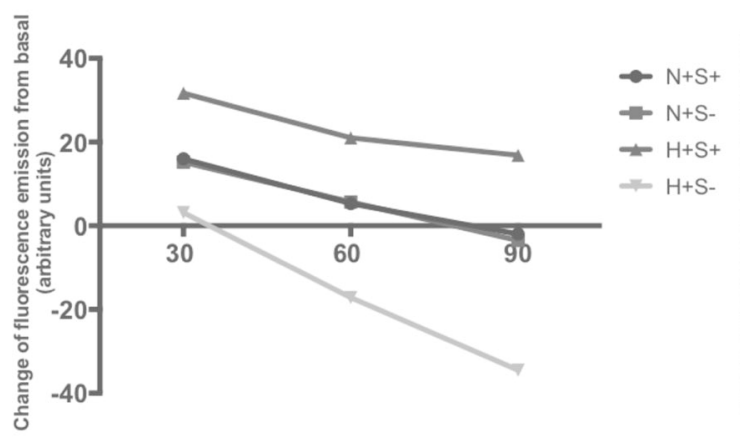

the scope of this study. We used a fluidic matrix to grow cells, since cells grown on a solid matrix more closely resemble the hypertensive state. Moreover, the artificial heart pump causes damage due to vascular fibrosis. Thus the presence of pulsation provides the homeostatic state and removal of pulsing produces the pathological state.

The data obtained support the concept that subjecting PASM cells from a normal neonatal $(<24 \mathrm{~h}$ age) pulmonary artery to in vitro stressors, it is possible to recapitulate the effect of the same stressors in the disease state. Normoxia together with $\pm 5 \%$ stretch from the resting length of the artery at physiological pulsation rate is a control. Hypoxia and loss of pulsation is what is seen in PAH. I find the highest cell detachment (death) rate among the normoxic population, indicating a normoxia-associated higher susceptibility to the adverse effects of strain than the hypoxic population.

\section{F:G actin ratio links vascular remodeling to the hypertensive phenotype}

$\mathrm{F}: \mathrm{G}$ actin is suggested as an endpoint in the cytoplasm because the greater the amount of G-actin that is present, the stronger is the hypertensive phenotype that is expressed as the cell loses the dynamic assembly of the cytoskeleton. To prove that stretched cells are comparable to cells seen in the vascular wall we took a structural approach that compares $\mathrm{F}$ to G-actin in the cytosol using LSC.

Our use of phantom contours through the application of LSC gives a more accurate analysis of actin fluorescence than can be achieved through the use of peripheral contouring in previously published studies [38]. Phantom integrates the fluorescence within each circle everywhere. We can measure which phantom is overlaid on top of each position. As F-actin fluorescence more thoroughly delineates cell boundaries, red channel F-actin fluorescence is used for the separation of the phantom contour lattice into background and cell-associated populations. The results of the two LSC methods were identical, demonstrating that the LSC is capable of visualizing and quantifying actin depolymerization in hypertensive myocytes, in a reporiducible manner, because $F: G$ actin ratios scored 3.2 (sum) or 3.1 (mean) in cultured hASM cells. The absence of pulsatile stretch alters ROS, low density lipoproteins (LDL) peroxidation and F:G actin, linking ROS to cytoskeleton disassembly. Although I established the validity of the LSC for this purpose, the insufficient availability of resources limited quantification of the induced $F: G$ actin ratio after challenging contractile myocytes with the four study treatments, in a 
hypoxia gradient- and pulsatile strain gradient-dependnet manner.

\section{Cell cycle entry}

P53 and Rb are key regulators of cell cycle. P27 is a key regulator of PASM proliferation through the hypoxia/PI3K/ AKT pathway and it convereges on hypoxia and ROS to promote cell cyle entry [39] as reviewed in Johar [40].

In this study, different treatments did not change the distribution of the cell cycle phases. The normal growing population was predominantly in Go/G1 phase. This finding is consistent with other findings that showed no significant increase in PASM growth under 5\% and $10 \%$ hypoxia. For example, Santilli's studies reported that the cells in the medial wall of the artery normally exist under conditions of low oxygen in rabbit aortas [41-43]. Santilli measured the concentration of transarterial wall oxygen in rabbit aortas by using an $\mathrm{O}_{2}$ microelectrode and found the lowest $\mathrm{O}_{2}$ concentrations in the medial wall of the artery, in comparison with the adventitia and lumen $[31,44,45]$. The $\mathrm{O}_{2}$ concentration was only $\sim 4 \%$ in the centre of the media, but $12 \%$ in the lumen and $8 \%$ in the adventitia. Scientists usually use $1-3 \%$ of $\mathrm{O}_{2}$ in studies related to proliferation [29, 41-43].

Chronic hypoxia-induced hypertension is a well-known model in which the decrease in alveolar oxygen pressure to $<70 \mathrm{mmHg}$ can induce a strong vasoconstrictor response, but this response is variable among animal species. The greatest effect is in cattle where short time chronic hypoxia causes acute vasoconstriction [46], while prolonged hypoxia results in remodeling of the distal pulmonary arterial branches $[47,48]$. With the level of hypoxia used in this study $\left(\mathrm{FiO}_{2}: 0.10\right), \mathrm{PO} 2$ in tissues is not reaching half of $21 \%$ at $40 \mathrm{mmHg}$. By undertaking $10 \% \mathrm{O}_{2}$, it takes the tissues to a physiological $\mathrm{pH}$. Previous studies standardized the model [18, 49]. Saini-Chohan [50] showed that $10 \% \mathrm{O}_{2}$ in vivo causes significant remodeling of the pulmonary arterial media in $72 \mathrm{~h}$. Those studies have also shown that $10 \% \mathrm{O}_{2}$ in vitro has a similar effect on proliferation of SM cells. Gradient hypoxia ranging from $1-4 \%$ and measurements of the actual amount of $\mathrm{O}_{2}$ dissolved in the monolayer under test conditions can be observed and used to optimize the system.

PASM cells regulate vascular resistance and luminal diameter. In this study, compared to normoxia, hypoxia induced significantly higher expression of desmin [Fig. 9a]. Hypoxic and normoxic hASM express the same level of $\beta$ actin in the presence of stretch. The lack of stretch leads to much lower expression of $\beta$-actin [Fig. 9a]. Serum deprivation for $48 \mathrm{~h}$ upregulated the basal expression of key proteins involved in different biomechanical and hypoxia pathways and their phospho-specific partners except for Src [Fig. 9]. This demonstrates that pulsatile stretch maintains the expression of SM-specific genes and contractility, while the absence of pulsatile stretch alters cytoskeleton assembly.

In hyperproliferative states such as PPHN, the plasticity of the resistant arteries is lost by an ongoing process of remodeling that implies a predominance of synthetic SM fibers $[1,8,9]$. The elevated levels of hypoxemia and oxidative stress contribute to disease progression by inducing proliferation [17] and protecting against cell cycle arrest, i.e. apoptosis or senescence $[12,15]$. The current analysis of cell cycle nuclear events by LSC indicates that the normal growing population in Go/G1 was predominant (97\% of the total population), with the majority of the max pixel events were mitotic. Different treatments did not induce apoptosis or proliferation differently from the control.

\section{Oxidative stress}

This current findings show that pulsatile strain increase total cytosolic ROS and endogenous superoxide anion release significantly in normoxic and hypoxic conditions in primary PASM fibers [Fig. 10a]. The effect of strain was predominant in increasing the superoxide anion release only under hypoxic conditions [Fig. 10b]. These data led us to assume that the increased generation of ROS is likely the mechanism that induces cell death in mechanically strained myocytes and that hypoxia independent of strain protects against such death.

\section{Significance}

These experiments provide pilot data necessary to characterize hypoxia and mechanical strain-induced regulation of the PPHN phenotypic vasculature in an animal model that manifests the disease in a similar pattern to human babies. We provided a structural approach amenable to prove that stretched cells are comparable to cells seen in the vascular wall. This work demonstrates that LSC, by a method utilizing a fluidic matrix to grow cells, is appropriate for identifying a role for pulsatile stretch in PPHN tissue remodeling. Furthermore, this work supports the hypothesis that hypoxia and mechanical strain induce the hypertensive phenotype in the vasculature of similar animal models. The findings obtained by LSC in vitro are amenable to validation in any model of interest in vivo. Identifying the concerted interplay between ROS/Reactive nitrogen species generation and signaling will lead to therapeutic targets to combate vascular remodeling in PPHN. The described evidence can be tested via clinical trials.

Previous studies have used immunoblotting for studying cell fate decisions. Western blotting is inadequate because it does not quantitatively provide the specific phenotype characteristics. The LSC overcomes the limitations of cell count by bromodeoxyuridine (BrdU) incorporation using 
flow cytometry, hence, LCS is favorable from the following prospectives: (1) LSC can be applied in situ, (2) PASM cells are challenging in terms of losing their adhesion characteristics when they are lifted, hence LSC is favorable compared to flow cytometry because it maintains the cell shape and integrity, (3) LSC allows signal quantification by immunostaining after subjecting the cells to any stressors simultaneously, i.e. pulsatile stretch with or without hypoxia, (4) LSC is very sensitive and reproducible, allowing exploration of very subtle differences, which would be lost by Western blotting due to inter-experimental and inter-gel variability, (5) LSC can be applied to cells or tissues by immunostaining compared to Western blotting or flow cytometry, which utilize only cell lysates or cells, respectively, (6) LSC can measure fluorescence in any compartment of the cell by identifying contouring around intracellular organelles, (7) LSC allows 3-dimensional measurement of markers at the cell surface and intracellularly, (8) LSC can correlate function with signaling, i.e., the more G-actin, the stronger is the phenotype as the cell loses the dynamic assembly of the cytoskeleton, (9) phantom module selection by LSC allows quantification of cytoplasmic $F: G$ actin as an endpoint of the effect of pulsatile strain together with or without hypoxia on PASM depolymerization in a visual way that is unavailable by Western blotting. Western blotting allows quantifying of the $F: G$ actin ratio by fractionation: a laborious method. The LSC method does not inform about the upstream triggers of hypoxia and mechanical strain or how they crosstalk, or what is the link to the cell cycle. It does, however, allow the investigator to correlate actin depolymerization with the phenotype characteristics quantitatively and in a visual format, and indicates that stretched cells are comparable to cells that are seen in the vascular wall.

Patients with Echocardiographic non-stretching pulmonary artery diameter would benefit from antioxidant therapy. By connecting known pathways of ROS generation and apoptosis with other cell fate decisions, such as cellular senescence and inflammatory signaling, future studies could uncover new targets for therapy of vascular remodeling in PPHN. Prevention of irreversible fibrotic medial thickening in PPHN would help reduce mortality in infants with PPHN and improves the opportunity for successful vasodilator therapies. Finally, tissue microarrays from PPHN patients can be obtained to correlate the presence of remodeling biomarkers with disease progression, survival, and response to treatment.

\section{Future research}

Although this study addresses primarily whether cyclic strain is associated or independent on hypoxia in the context of apoptosis, the question of whether mechanical stretch combined with hypoxia upregulates DNA synthesis remains unaddressed. Future research can examine if the inhibition of p53 or cyclin-dependent kinase inhibitor 2 A (p16) signaling will suppress the sysnthetic phenotype. This can be demonstrated using Lentivirus-delivered small-hairbin RNA shRNA-mediated p53 or p16 depletion in PASM cells, challenged with stretch or hypoxia. Further, the growth suppressive mechanisms underlying control cells compared to PASM cells challenged with the same stressors can be addressed, e.g., testing the requirement of components of the DNA damage response pathway other than p53, such as cyclin-dependent kinase inhibitor $1 \mathrm{~A}$ (p21), ataxiatelangiectasia mutated (ATM), checkpoint kinase 2 (CHK2) or other than $\mathrm{pRb}$ in the proliferative phenotype. Other research to address if the inhibition of pERK signaling will suppress hypoxia/stretch-induced proliferation using Lentiviruses delivered shRNA-mediated pERK depletion (ligand and receptor) or the research that uses the expression of a dominant-negative mutant of the essential receptor is required. Whether the cells that are made deficient in ERK acquire resistance to proliferation can be studied using simple growth assays. It is expected that cells subjected to stretch or hypoxia will grow compared to control. The above selected genes can be targeted by Lentivirus-mediated stable RNAi (interference) to study their differential roles in modulating other signaling networks that could be involved in proliferation. This study did not attempt to study each treatment independently, instead, it studied the interaction. In the absence of pulsatile strain, one expects more oxidative stress i.e. high LDL peroxidation, how this links to $\mathrm{F}: \mathrm{G}$ actin and to the cell cycle is yet to be investigated.

Proliferation can be assayed by Ki-67 staining to confirm the LSC data. Apoptosis is determined conventionally by propidium iodide fluorescence-activated cell sorting (FACS) assay. According to whether cell death type is intrinsic or extrinsic, apoptosis markers such as annexin $\mathrm{V}$, caspase 3- and 9 activation, Bcl-2-associated $\mathrm{X}$ protein/Bcell lymphoma-2 (Bax/Bcl-2) ratio, Bcl-2-associated $\mathrm{X}$ protein/B-cell lymphoma — extra large (Bax/Bcl-XL) ratio, Bax localization (immunocytochemistry and subcellular fractionation), mitochondrial permeability by JC1 fluorescence, cytochrome c by subcellular fractionation followed by Western blot [51, 52] can be examined as confirmatory methods, however, this is beyond the scope of this study.

\section{Limitations and solutions}

Limitations of LSC include the following: (1) avoiding background formation on the flexer-cell membrane because the background interferes with the fluorescence of the nucleus and cytosol. A single-cell approach cannot apply. Adding an inhibitor can demonstrate higher levels 
of regulation. (2) DCF limitations include: first, hydrogen peroxide $\mathrm{H}_{2} \mathrm{O}_{2}$-dependent oxidation of DCFH to DCF occurs slowly, if at all, in the absence of ferrous iron. Second, DCFH oxidation is reliant on metal-catalyzed oxidation reactions, thus mitochondrial heme-containing cytochromes, peroxidases and a variety of other organic acid or protein-complexed transition metals catalyze DCFH oxidation. Third, the intracellular deacetylation of DCFH-diacetate to DCFH does not assure detection of intracellular redox reactions of whatever chemical origin. Following deacetylation, DCFH can back-diffuse into the extracellular compartment to undergo further reactions. However, the above limitations affect both the experiment and the control; therefore, they do not invalidate our data.

\section{Data availability}

All the data generated or analyzed during this study are included in this published article.

Acknowledgements A minor portion of the in vitro PASM model was obtained as a gift by Dr. Shyamala Dakshinamurti, at the Physiology and Pathophysiology Department, the University of Manitoba. Antibodies for immunoblotting, fast-cast SDS gels and hASM cells were obtained as a gift by Dr. Adrian West at the Physiology and Pathophysiology Department, the University of Manitoba, Canada. The University of Manitoba supported the language revision.

Author's contribution DJ contributed to conception, data acquisition and analysis. All the authors contributed to writing and reviewing the manuscript. DJ submitted the manuscript and provided the PRISM 6.0 (GraphPad Software, Inc. San Diego, CA) and the Endnote 8X softwares. Original data can be requested from DJ.

\section{Compliance with ethical standards}

Conflict of interest The authors declare that they have no conflict of interest.

\section{References}

1. Hall SM, Gorenflo M, Reader J, Lawson D, Haworth SG. Neonatal pulmonary hypertension prevents reorganisation of the pulmonary arterial smooth muscle cytoskeleton after birth. J Anat. 2000;196(Pt 3):391-403.

2. Lakshminrusimha S, Steinhorn RH. Pulmonary vascular biology during neonatal transition. Clin Perinatol. 1999;26:601-19.

3. Haworth SG. Development of the normal and hypertensive pulmonary vasculature. Exp Physiol. 1995;80:843-53.

4. Walsh-Sukys MC, Tyson JE, Wright LL, Bauer CR, Korones SB, Stevenson DK, et al. Persistent pulmonary hypertension of the newborn in the era before nitric oxide: practice variation and outcomes. Pediatrics. 2000;105(1 Pt 1):14-20.

5. Baquero H, Soliz A, Neira F, Venegas ME, Sola A. Oral sildenafil in infants with persistent pulmonary hypertension of the newborn: a pilot randomized blinded study. Pediatrics. 2006;117:1077-83.

6. Walsh MC,Stork EK, Persistent pulmonary hypertension of the newborn. Rational therapy based on pathophysiology. Clin Perinatol. 2001;28:609-27.
7. Hernandez-Diaz S, Van Marter LJ, Werler MM, Louik C, Mitchell AA. Risk factors for persistent pulmonary hypertension of the newborn. Pediatrics. 2007;120:e272-82.

8. McLeod KA, Gerlis LM, Williams GJ. Morphology of the elastic pulmonary arteries in pulmonary hypertension: a quantitative study. Cardiol Young-. 1999;9:364-70.

9. Tozzi CA, Christiansen DL, Poiani GJ, Riley DJ. Excess collagen in hypertensive pulmonary arteries decreases vascular distensibility. Am J Respir Crit Care Med. 1994;149:1317-26.

10. Johar D, Bernstein LH. A targeted approach toward more accurate assessment of hypertension. Egypt $\mathrm{J}$ Chest Dis Tuberc. 2017;66:517-36.

11. Gong Y, Yi M, Fediuk J, Lizotte PP, Dakshinamurti S. Hypoxic neonatal pulmonary arterial myocytes are sensitized to ROSgenerated 8-isoprostane. Free Radic Biol Med. 2010;48:882-94.

12. Wohrley JD, Frid MG, Moiseeva EP, Orton EC, Belknap JK, Stenmark KR. Hypoxia selectively induces proliferation in a specific subpopulation of smooth muscle cells in the bovine neonatal pulmonary arterial media. J Clin Invest. 1995;96:273-81.

13. Dakshinamurti S. Pathophysiologic mechanisms of persistent pulmonary hypertension of the newborn. Pediatr Pulmonol. 2005;39:492-503.

14. Pak O, Sommer N, Hoeres T, Bakr A, Waisbrod S, Sydykov A, et al. Mitochondrial hyperpolarization in pulmonary vascular remodeling. itochondrial uncoupling protein deficiency as disease model. Am J Respir Cell Mol Biol. 2013;49:358-67.

15. Hall SM, Hislop AA, Wu Z, Haworth SG. Remodelling of the pulmonary arteries during recovery from pulmonary hypertension induced by neonatal hypoxia. J Pathol. 2004;203:575-83.

16. Su BY, Shontz KM, Flavahan NA, Nowicki PT. The effect of phenotype on mechanical stretch-induced vascular smooth muscle cell apoptosis. J Vasc Res. 2006;43:229-37.

17. Postolow F, Fediuk J, Nolette N, Hinton M, Dakshinamurti S. Hypoxia and nitric oxide exposure promote apoptotic signaling in contractile pulmonary arterial smooth muscle but not in pulmonary epithelium. Pediatr Pulmonol. 2011;46:1194-208.

18. Fike CD, Kaplowitz MR. Effect of chronic hypoxia on pulmonary vascular pressures in isolated lungs of newborn pigs. J Appl Physiol. 1994;77:2853-62.

19. Qu MJ, Liu B, Wang HQ, Yan ZQ, Shen BR, Jiang ZL. Frequency-dependent phenotype modulation of vascular smooth muscle cells under cyclic mechanical strain. J Vasc Res. 2007;44:345-53.

20. Birukov KG. Cyclic stretch, reactive oxygen species, and vascular remodeling. Antioxid Redox Signal. 2009;11:1651-67.

21. Waypa GB, Marks JD, Mack MM, Boriboun C, Mungai PT, Schumacker PT. Mitochondrial reactive oxygen species trigger calcium increases during hypoxia in pulmonary arterial myocytes. Circ Res. 2002;91:719-26.

22. Sotoudeh M, Li YS, Yajima N, Chang CC, Tsou TC, Wang Y, et al. Induction of apoptosis in vascular smooth muscle cells by mechanical stretch. Am J Physiol Heart Circ Physiol. 2002;282: H1709-16.

23. Su BY, Shontz KM, Flavahan NA, Nowicki PT. The effect of phenotype on mechanical stretch-induced vascular smooth muscle cell apoptosis. J Vasc Res. 2006;43:229-37.

24. Kass DA. Ventricular arterial stiffening: integrating the pathophysiology. Hypertension. 2005;46:185-93.

25. Ali MH, Pearlstein DP, Mathieu CE, Schumacker PT. Mitochondrial requirement for endothelial responses to cyclic strain: implications for mechanotransduction. Am J Physiol Lung Cell Mol Physiol. 2004;287:L486-96.

26. Inoue N, Kawashima S, Hirata KI, Rikitake $Y$, Takeshita S, Yamochi W, et al. Stretch force on vascular smooth muscle cells enhances oxidation of LDL via superoxide production. Am J Physiol. 1998;274(6 Pt 2):H1928-32. 
27. Shimoda LA, Manalo DJ, Sham JS, Semenza GL, Sylvester JT. Partial HIF-1alpha deficiency impairs pulmonary arterial myocyte electrophysiological responses to hypoxia. Am J Physiol Lung Cell Mol Physiol. 2001;281:L202-8.

28. Shimoda LA, Sham JS, Shimoda TH, Sylvester JT. L-type $\mathrm{Ca}(2+)$ channels, resting $[\mathrm{Ca}(2+)](\mathrm{i})$, and ET-1-induced responses in chronically hypoxic pulmonary myocytes. Am J Physiol Lung Cell Mol Physiol. 2000;279:L884-94.

29. Musharaf I, Hinton M, Yi M, Dakshinamurti S. Hypoxic challenge of hyperoxic pulmonary artery myocytes increases oxidative stress due to impaired mitochondrial superoxide dismutase activity. Pulm Pharmacol Ther. 2018;48:195-202.

30. Wang H, Joseph JA. Quantifying cellular oxidative stress by dichlorofluorescein assay using microplate reader. Free Radic Biol \& Med. 1999;27:612-6.

31. Munzel T, Afanas'ev IB, Kleschyov AL, Harrison DG. Detection of superoxide in vascular tissue. Arterioscler Thromb Vasc Biol. 2002;22:1761-8

32. Ertan C, Tarakci N, Ozeke O, Demir AD. Pulmonary artery distensibility in chronic obstructive pulmonary disease. Echocardiography. 2013;30:940-4.

33. Kolipaka A, Woodrum D, Araoz PA, Ehman RL. MR elastography of the in vivo abdominal aorta: a feasibility study for comparing aortic stiffness between hypertensives and normotensives. J Magn Reson Imaging. 2012;35:582-6.

34. Lau EM, Iyer N, Ilsar R, Bailey BP, Adams MR, Celermajer DS. Abnormal pulmonary artery stiffness in pulmonary arterial hypertension: in vivo study with intravascular ultrasound. PLoS ONE. 2012; 7:e33331.

35. Wedgwood S, Lakshminrusimha S, Schumacker PT, Steinhorn RH. Cyclic stretch stimulates mitochondrial reactive oxygen species and Nox4 signaling in pulmonary artery smooth muscle cells. Am J Physiol Lung Cell Mol Physiol. 2015;309:L196-203.

36. Dick AS, Ivanovska J, Kantores C, Belcastro R, Keith Tanswell A, Jankov RP. Cyclic stretch stimulates nitric oxide synthase-1-dependent peroxynitrite formation by neonatal rat pulmonary artery smooth muscle. Free Radic Biol Med. 2013;61:310-9.

37. Monica RS, Stephen W, Lyubov C, Gina AK, Satyan L, Paul TS, et al. Cyclic stretch induces inducible nitric oxide synthase and soluble guanylate cyclase in pulmonary artery smooth muscle cells. Int J Mol Sci. 2013;14:4334-48.

38. Fediuk J, Gutsol A, Nolette N, Dakshinamurti S. Thromboxaneinduced actin polymerization in hypoxic pulmonary artery is independent of Rho. Am J Physiol Lung Cell Mol Physiol. 2012;302:L13-26.

39. Luo Y, Xu DQ, Dong HY, Zhang B, Liu Y, Niu W, et al. Tanshinone IIA inhibits hypoxia-induced pulmonary artery smooth muscle cell proliferation via Akt/Skp2/p27-associated pathway. PLoS ONE. 2013;8:e56774.

40. Johar D. Cytoskeletal remodeling and regulation of cell fate in the hypertensive neonatal pulmonary artery in response to stress. J Cell Physiol. 2018;233:2146-61.

41. Santilli SM, Wernsing SE, Lee ES. The effect of supplemental oxygen on the transarterial wall oxygen gradients at a prosthetic vascular graft to artery anastomosis in the rabbit. Ann Vasc Surg. 2001;15:435-42.

42. Santilli SM, Tretinyak AS, Lee ES. Transarterial wall oxygen gradients at the deployment site of an intra-arterial stent in the rabbit. Am J Physiol Heart Circ Physiol. 2000;279:H1518-25.

43. Santilli SM, Wernsing SE, Lee ES. Transarterial wall oxygen gradients at a prosthetic vascular graft to artery anastomosis in the rabbit. J Vasc Surg. 2000;31:1229-39.

44. Remillard CV, Yuan XJ. Activation of K channels: an essential pathway in programmed cell death. Am J Physiol Lung Cell Mol Physiol. 2004;286:L49-67.

45. Jian Chen MM, Wang Y-X, Dong M-Q, Zhang BO, Luo Y, Niu $\mathrm{W}$, et al. Reoxygenation reverses hypoxic pulmonary arterial remodeling by inducing smooth muscle cell apoptosis via reactive gen species-mediated mitochondrial dysfunction. J Am Heart Assoc. 2017;6:e05602.

46. Newman JH, Holt TN, Hedges LK, Womack B, Memon SS, Willers ED, et al. High-altitude pulmonary hypertension in cattle (brisket disease): Candidate genes and gene expression profiling of peripheral blood mononuclear cells. Pulm Circ. 2011;1:462-9.

47. Bartsch P, Mairbaurl H, Swenson ER, Maggiorini M. High altitude pulmonary oedema. Swiss Med Wkly. 2003;133:377-84.

48. Glover GH, Newsou L. Further studies on brisket disease. J Agric Res. 1918;15:409.

49. Haworth SG, Hislop AA. Effect of hypoxia on adaptation of the pulmonary circulation to extra-uterine life in the pig. Cardiovasc Res. 1982;16:293-303.

50. Saini-Chohan HK, Dakshinamurti S, Taylor WA, Shen GX, Murphy R, Sparagna GC, et al. Persistent pulmonary hypertension results in reduced tetralinoleoyl-cardiolipin and mitochondrial complex II + III during the development of right ventricular hypertrophy in the neonatal pig heart. Am J Physiol Heart Circ Physiol. 2011;301:H1415-24.

51. Ghavami S, Eshraghi M, Kadkhoda K, Mutawe MM, Maddika S, Bay GH, et al. Role of BNIP3 in TNF-induced cell death--TNF upregulates BNIP3 expression. Biochim Biophys Acta. 2009; 1793:546-60.

52. Ghavami S, Yeganeh B, Stelmack GL, Kashani HH, Sharma P, Cunnington R, et al. Apoptosis, autophagy and ER stress in mevalonate cascade inhibition-induced cell death of human atrial fibroblasts. Cell Death Dis. 2012;3:e330. 